\title{
Design of new patient-reported outcome measures to assess quality of life, symptoms and treatment satisfaction in patients with abdominal aortic aneurysm
}

\begin{tabular}{|r|l|}
\hline Journal: & British Journal of Surgery \\
\hline Manuscript ID & BJS-1877-Dec-15.R1 \\
\hline Wiley - Manuscript type: & Original Article \\
\hline Complete List of Authors: & $\begin{array}{r}\text { Peach, George; St George's Healthcare NHS Trust, St George's Vascular } \\
\text { Institute } \\
\text { Romaine, Jackie; Health Psychology Research Ltd } \\
\text { Wilson, Alison; Health Psychology Research Ltd } \\
\text { Holt, Peter; St George's Vascular Institute } \\
\text { Thompson, Matt; St George's Hospital Medical School, Vascular Surgery } \\
\text { Hinchliffe, Robert; St. George's Healthcare NHS Trust, St. George's } \\
\text { Vascular Institute } \\
\text { Bradley, Clare; Health Psychology Research Ltd }\end{array}$ \\
\hline Keywords: & $\begin{array}{l}\text { Quality of life, aortic aneurysm, patient-reported outcome measures, } \\
\text { symptoms, treatment satisfaction }\end{array}$ \\
\hline \multicolumn{2}{|l}{} \\
\hline
\end{tabular}




\title{
Design of new patient-reported outcome measures to assess quality of life, symptoms and treatment satisfaction in patients with abdominal aortic aneurysm
}

\author{
G Peach ${ }^{1}$, J Romaine ${ }^{2}$, A Wilson ${ }^{2}$, PJE Holt ${ }^{1}$, MM Thompson ${ }^{1}$, RJ Hinchliffe ${ }^{1}$, C \\ Bradley $^{2}$
}

${ }^{1}$ St. George's Vascular Institute, $4^{\text {th }}$ Floor St. James Wing, St. George's Healthcare NHS Trust, London, SW17 0QT, UK.

${ }^{2}$ Health Psychology Research Ltd, Orchard Building, Royal Holloway, University of London, Egham, Surrey, TW20 0EX, UK.

Corresponding author: George Peach c/o St. George's Vascular Institute, $4^{\text {th }}$ Floor St. James Wing, St. George's Healthcare NHS Trust, London, SW17 0QT, UK. (+447946648 584) gpeach@doctors.org.uk

Funding acknowledgement: This work was part funded by a Medical Research Grant from the St George's Charitable Foundation. It was also supported by a Royal College of Surgeons Pump Priming Grant. Peter Holt is a Clinician Scientist financially supported by the National Institute for Health Research (NIHR-CS011-008). No other external funding is declared. The NIHR had no role in study design, data collection and analysis, decision to publish, or preparation of the manuscript.

Category: Original Article

\section{Competing interests}

Clare Bradley is the copyright owner of the AneurysmDQoL, AneurysmTSQ and AneurysmSRQ which, along with other questionnaires designed by CB and her research team, are licensed to others to use through Health Psychology Research (HPR) Ltd, of which she is CEO and majority shareholder. Licence fees are charged to commercial companies who license the questionnaires. Clinicians, 
academics and other non-commercial users are asked to pay a small

administration charge but no licence fee. Licence agreements are provided to students free of all charges.

http://mc.manuscriptcentral.com/bjs 


\begin{abstract}
Introduction: No condition-specific patient-reported outcome measures existed for patients with abdominal aortic aneurysm (AAA). The aim of this work was to develop three questionnaires to assess quality of life (QoL), symptoms and treatment satisfaction in patients with AAA.
\end{abstract}

Method: Semi-structured interview techniques were used to explore patients' experiences of having AAA in a series of focus groups and in-depth interviews. The information gathered was used to inform design and selection of items for the new tools, with the overall structure of the new questionnaires based upon tools developed previously for patients with diabetes and other conditions.

Results: 54 patients (51 men; 3 women; mean age 71.9yrs) were recruited from 4 NHS Trusts to participate in focus groups or interviews, either whilst under surveillance or following AAA repair (using open or endovascular techniques). The Aneurysm-Dependent Quality of Life Questionnaire (AneurysmDQoL) is an individualised measure of the impact of AAA on patients' QoL. 23 domains were chosen specifically for their relevance to patients with AAA with a further 2 overview items to assess overall QoL and the impact of AAA on QoL. The Aneurysm Symptom Rating Questionnaire (AneurysmSRQ) is a 44-item measure assessing physical and psychological symptoms reported by patients with AAA. The Aneurysm Treatment Satisfaction Questionnaire (AneurysmTSQ) contains 11 items , suitable for patients pre- and post-surgical intervention.

Conclusion: The iterative development process reported here has confirmed that these three new tools have good face and content validity for patients with AAA. Psychometric analyses assessing structure and construct validity of the tools will be reported separately.

Keywords 
Quality of life; aortic aneurysm; patient-reported outcome measure; treatment satisfaction; symptoms; AneurysmDQoL; AneurysmSRQ; AneurysmTSQ

\section{Introduction}

In the UK, abdominal aortic aneurysms (AAA) affect $5-10 \%$ of men and $1.5 \%$ of women between the ages of 65 and 79 and constitute a significant cause of mortality in this age group. ${ }^{1}$ Due to the risk of rupture, patients diagnosed with AAA usually undergo elective repair once the aneurysm reaches threshold size $(5.5 \mathrm{~cm})$. Techniques of AAA repair have evolved significantly in recent years with large numbers now treated with endovascular repair (EVAR) rather than open repair (OR). As a result of these advances and rigorous Quality Improvement Programmes, surgical morbidity and mortality have fallen dramatically and these parameters are therefore less useful than previously as the sole markers of surgical quality. ${ }^{2}$ Additionally and importantly, measures of quality of life (QoL), symptoms and treatment satisfaction allow evaluation of outcomes from the patients' perspectives. This allows clinicians to target those issues that are most important to patients and strive for even higher quality care rather than simply avoiding adverse outcomes. For this reason the last few years have seen the UK Department of Health embark on a nationwide initiative to encourage the use of patient-reported outcome measures (PROMs), both in the surgical specialties generally and more specifically in aortic aneurysm surgery. ${ }^{34}$

In the absence of a validated aneurysm-specific QoL measure, all previous studies of QoL in patients with AAA have used generic tools. Systematic review of these studies demonstrated that there was no clear consensus about the overall impact of AAA (or AAA repair) on QoL. 5 Meta-analysis of existing data did provide some additional clarification, suggesting that QoL may be negatively impacted after AAA repair. ${ }^{6}$ However, the pattern of change over time (particularly beyond 12 months post-intervention) and any differences between OR and EVAR may have been obscured by the use of generic tools and heterogeneity of data in the included studies. Many of the studies used generic health status measures instead of QoL instruments and it is important to 
distinguish between the two if we are not to be misled: health and QoL do not necessarily improve/deteriorate in tandem. ${ }^{7}$ Furthermore, very little is known about symptoms experienced or treatment satisfaction in these patients.

The aim of this work was to design three new condition-specific questionnaires based on the experiences of patients with AAA to provide robust, separate assessments of QoL, symptoms, and treatment satisfaction for use in clinical practice, audit and research.

\section{Methods}

\section{Recruitment of patients}

Patients were recruited from 4 English NHS Trusts: St George's University Hospitals NHS Foundation Trust (London), North Bristol NHS Trust, Norfolk and Norwich University Hospitals NHS Trust and Worcestershire Acute Hospitals NHS Trust. All participants had undergone AAA repair within the preceding 24 months (OR or EVAR) or were enrolled in preoperative surveillance with an aneurysm that was below the threshold size for intervention. Men and women were invited and there was no age constraint. Only English-speaking patients were invited to take part.

\section{Focus groups}

Patients were identified using a purposive sampling technique (maximum variation) and assigned to focus groups with similar patients (i.e. all preintervention or OR or EVAR). This was done to prevent confusion between participants who had experienced different forms of treatment. The National Research Ethics Service (NRES Committee - London Chelsea - 11/LO/1416) approved the process of patient recruitment prior to the start of the study and patients provided written consent at each stage. 
The number of focus groups was determined using a 'theme-saturation' model, which dictates that no further focus groups are necessary once there are no new themes being presented by participants. ${ }^{8}$ Focus groups were moderated by a trainee vascular surgeon (GP) and a health psychologist with extensive experience in questionnaire design (CB). A semi-structured format was used to explore patients' experiences in relation to QoL, symptoms and treatment satisfaction at each stage in the treatment pathway using open-ended questions. The discussion included diagnosis, surveillance, preoperative investigations and, where applicable, intervention, recovery and follow-up. More sensitive topics (such as bowel or sexual function) were not broached by the facilitators during focus groups to avoid causing embarrassment to participants but were discussed during in-depth interviews. Written notes and audio recordings were made during each session to allow subsequent transcription.

Transcripts underwent content analysis to allow identification of the themes raised by group participants. Individual issues were listed and grouped into themes, with continual re-evaluation after each group and addition of new issues/themes as they emerged. Newly identified themes were then re-explored in greater depth at subsequent focus groups. This process clarified when themesaturation had been reached and resulted in a single list of all aspects of QoL, symptoms and treatment satisfaction that had been raised by the participants. (Table 2 - Supplementary material).

\section{Questionnaire design}

The themes identified during the focus groups then determined the aspects of QoL, symptoms and treatment satisfaction that were included in drafts of the three new questionnaires. To minimize the need for linguistic validation, the wording and structure of questions in the new tools was based upon items from existing questionnaires previously developed with other patient groups and validated by $\mathrm{CB}$ as described below. The number of items in each of the new questionnaires was not predetermined, but instead resulted from selection of suitable items from a pre-existing item bank to address the domains relevant to 
patients with AAA. If no previous bank item existed (or could be adapted) to cover a QoL domain raised in the focus groups, a new item was created with specialist linguistic input (to facilitate future translations into other languages) before being tested in interviews.

\section{AneurysmDQoL}

The overall format of the AneurysmDQoL and many of the individual items were based upon those in the Audit of Diabetes-Dependent Quality of Life (ADDQoL) and associated questionnaires designed for use by people with other conditions. The ADDQoL was designed by $\mathrm{CB}$ and colleagues to improve on previous condition-specific measures which were not individualised and often contained a mixture of items measuring symptoms, functional status and treatment satisfaction, with a minority including items genuinely measuring QoL. The ADDQoL is the most widely used of the various -DQoL measures and is linguistically validated in more than 60 languages. 9-17 The design of the ADDQoL was influenced by the principles underpinning the SEIQoL (Schedule for the Evaluation of Individual QoL) interview methodology. ${ }^{18}$ The guiding definition of QoL provided by the ADDQoL, as with the SEIQoL, is 'how good or bad you feel your life to be'. The SEIQoL allows respondents to select the aspects of their life of importance for their QoL before rating them for quality, thereby providing an individualised measure of QoL. The -DQoLs differ from the SEIQoL by being condition-specific and questionnaire measures rather than a generic interview tool but are similarly individualised in two different ways: first, a not applicable option is provided for items that may not be applicable to everyone (eg working life) and, secondly, a rating of the importance of each aspect of life is elicited as well as a rating of the impact of the condition on that aspect of their life (see figure 1). Thus each item consists of two rating scales to measure impact and importance and the two scores are multiplied to give a Weighted Impact (WI) score. . The AneurysmDQoL, thereby provides a personalised assessment of the impact of AAA on an individual's QoL 
In addition, the AneurysmDQoL also includes two broad overview items. The first asks respondents to rate their present QoL and the second asks how their quality of life would be if they had not had an aneurysm.

\section{AneurysmSRQ}

Question format of the AneurysmSRQ was based on tools developed previously by $\mathrm{CB}$ and colleagues for patients with a number of long-term conditions. 1920

In the first part of each question, respondents are asked to indicate whether they had experienced a particular symptom at all in recent weeks (defined as 'about four weeks'). For those who had experienced that symptom, the second part of the question asks how much it had bothered them. Responses to the second part of the question are given using a 4-point scale from 'not at all' 'to 'a lot'.(Fig 2).

\section{AneurysmTSQ}

The AneurysmTSQ was based on the Diabetes Treatment Satisfaction Questionnaire (DTSQ) and associated questionnaires for other conditions. 21-26 For each question in the AneurysmTSQ, patients are asked to respond using a 7point scale where a higher score indicates greater satisfaction with treatment (Fig. 3).

Since questionnaires were to be tested in patient interviews, all patientidentified issues were included in the initial drafts even if they were considered to be uncommon or unrelated to having an aneurysm, or had only been mentioned by one or two participants. Several additional items were also incorporated into the drafts to assess more sensitive symptoms including bowel function and sexual function, which may not have been mentioned by patients in a focus-group setting, but where there is evidence to suggest that AAA or its repair may have a negative impact. ${ }^{27-29}$

\section{Pilot interviews and questionnaire refinement}


In the next stage of development, the draft questionnaires were refined through in-depth interviews. In these interviews, participants were asked to work through each of the questionnaires in turn, reading the questions out and 'thinking aloud' so that interviewers could see when they were having difficulty reading or comprehending an item. This technique has been well proven over many years of developing similar tools. ${ }^{9} 30$ Participants were also given the opportunity to identify any additional issues that they felt had not been covered in the new tools.

\section{Results}

Nine focus groups were held during the initial phase of development (6 EVAR; 2 OR; 1 surveillance). In total, these involved 41 patients with AAA, with between 3 and 6 participants in each group. Though the majority of groups were with EVAR patients for logistic reasons, theme saturation suggested no further groups were necessary for either OR or surveillance patients. Thirteen in-depth interviews were then carried out during the subsequent refinement process.

(Table 1)

\section{Aneurysm-Dependent Quality of Life Questionnaire (AneurysmDQoL)}

In all of the focus groups for patients who had already undergone aneurysm repair (OR or EVAR), there were reports of AAA-related issues that could have negatively impacted their QoL (Table 2). Preoperative anxiety was particularly prevalent, with participants mentioning this spontaneously in 8 of the 9 focus groups and describing feelings of having a 'ticking time-bomb inside'. Anxiety about surgical intervention was also noted.

Participants in 2 groups (both EVAR) reported feelings of relief once their aneurysm was repaired, using phrases such as 'I felt happy to be alive', 'I had a near miss' and 'it was as if the bomb had been defused'. One patient (EVAR group) also said that they valued each day more since having the aneurysm repaired. However, relief of anxiety following intervention was certainly not 
universal. With many having experienced no preoperative symptoms, participants in 4 groups ( 3 EVAR, 1 OR) expressed concerns about the possibility of other occult illnesses and how they would ever know if any 'problem' were to arise with their aneurysm repair.

Another commonly arising theme was the impact of restricted activity on QoL. This was mentioned in 6 groups (all EVAR) and largely related to patients feeling that they had to limit their physical activity (as opposed to being physically incapable of doing things). In a small subset of patients (e.g. commercial drivers) there were financial implications due to being prohibited from working with an untreated aneurysm. Other notable QoL themes raised by participants included failure to return to preoperative levels of well-being following intervention; impact on relationships with family members; and the fact that some patients felt unprepared for the severity of the operation or complications when they arose.

The initial draft of the AneurysmDQoL contained 25 items in total. Following the first 2 overview items, there were 23 domain-specific items addressing the impact of AAA on multiple patient-identified aspects of life of importance for QoL (Table 2). The final item on the questionnaire was a free-text question, to allow patients to identify any other ways in which QoL is impacted by having had AAA.

In-depth interviews resulted in several minor modifications to the AneurysmDQoL. To improve patients' understanding of the stem question, the wording was changed from 'If I had not had an aneurysm, my quality of life would be...' to 'If I had never had an aneurysm...'. This was because a number of participants misinterpreted this to be about how their quality of life would be if they had not had an aneurysm repair rather than the actual condition. For example, some patients commented that if they had not had an aneurysm repair they would be dead. The change to the wording improved participants' understanding that the item was asking them to consider their QoL at time of questionnaire completion and how they feel this would be different if they had never had an aneurysm (whether repaired or not). Wording of the discomfort 
item was also changed, with participants finding the words 'physical discomfort' easier to understand than 'bodily discomfort'.

In a draft version of the AneurysmDQoL, there were three items relating to cognitive function, which asked about 'memory', 'ability to concentrate' and 'ability to think quickly and clearly'. However, a composite form of this question ultimately proved to detect as much impact as the three separate items taken together and the composite item was therefore retained in their place (Item 22, Appendix 1).

None of the participants identified any additional aneurysm-related QoL issues that were not already covered by the questionnaire. The final version contained 23 domain-specific items plus two overview items and a single free-text question about any other ways that QoL is affected. One domain specific item ('The amount I value each day') was ultimately removed during validation (to be reported separately), resulting in 22 domain specific items.

\section{Aneurysm Symptom Rating Questionnaire (AneurysmSRQ)}

During focus groups, patients reported a wide range of symptoms that they attributed to their aneurysm or its repair (Table 2). The most common of these was pain, with leg pain, lower back pain, abdominal pain and buttock pain being the most common (reported in 7, 5, 4 and 4 groups respectively). Other lower limb symptoms included swelling, numbness, weakness and heaviness. In addition to pain and limb symptoms, there were also a number of more generalized symptoms that were frequently mentioned. Participants in 7 of the 8 postoperative groups (all 6 EVAR groups and 1 OR group) commented on a feeling of marked lethargy for many months post-intervention. Low mood and weight loss were also noted in 4 groups each, with general weakness, decreased activity, profuse sweating, significant bruising, and poor appetite each mentioned in at least two groups. 
The initial draft of the AneurysmSRQ comprised 43 items asking about the specific physical, mental and psychological symptoms that were identified during focus groups plus 3 free-text items allowing patients to identify any additional symptoms that had not been covered elsewhere. Interviews provided the opportunity to discuss more sensitive topics that were not raised during focus groups. The interviews confirmed that these issues were experienced by patients and warranted inclusion in the AneurysmSRQ with more than $40 \%$ of interviewees reporting some upset in gastrointestinal function and over $60 \%$ reporting symptoms related to sexual dysfunction. The interview stage also resulted in the amendment or removal of several items that participants found difficult to understand or were not deemed relevant. These included those relating to general muscle pains, hallucinations, lumps under the skin and wound infection. A number of completely new items were also added after being identified as important by interviewees. These included avoidance of sexual activity (as distinct from problems with sexual function and loss of interest in sex which were in the original draft), feeling faint/lightheaded, difficulty thinking quickly and clearly and changes in bowel function. Furthermore, items were reordered to group symptoms into themes (e.g. gastrointestinal symptoms or pain etc.) so that the questionnaire followed a more logical sequence. The final version contained 44 items and 2 blank items for free-text describing any additional symptoms.

\section{Aneurysm Treatment Satisfaction Questionnaire (AneurysmTSQ)}

When it came to discussion of treatment satisfaction, a range of issues were highlighted (Table 2), though the most frequently reported concern was that patients didn't feel it had been made clear to them how serious their condition was. This related to a lack of information about likely side-effects (as opposed to complications covered in the preoperative consent process) and how much intervention might affect them both mentally and physically. Similarly, patients in six of the nine focus groups felt that that they had been given insufficient information about whether they should avoid physical exertion and whether certain activities, such as air travel, were safe pre- or postoperatively. Patients 
also frequently commented ( 6 of 9 groups) that they had not been given any choice about the type of intervention they would have for their aneurysm (i.e. OR or EVAR) and one elderly woman patient was distressed that she had had an OR and would have preferred EVAR. Some appeared not to be concerned by the lack of choice, however, and felt that the surgeon knew best and that they would not have minded what sort of operation they had. Other reported factors reducing satisfaction included insufficient time for consent, little contact with the surgeon and a lack of feedback about scan results. Interestingly, however, patients generally described feeling positively reassured by follow-up scans and clinic visits, rather than seeing them as a burden or source of anxiety.

In the AneurysmTSQ, patients are asked to evaluate their experiences of AAA treatment (including any monitoring or surveillance) over the preceding few weeks. The initial draft contained 15 items related to specific elements of treatment and monitoring, including overall treatment, convenience, discomfort, information, feedback, support, follow-up, demands of treatment and monitoring, understanding and satisfaction with type of operation (i.e. OR or EVAR). As in the AneurysmDQoL and AneurysmSRQ, there was also a final open question to allow respondents to mention any particular areas of satisfaction or dissatisfaction that had not already been covered.

Four items were removed from the AneurysmTSQ following in-depth interviews. Three of these were poorly understood by patients or unnecessarily repetitive and related to demands of treatment; flexibility of treatment and how well they felt the operation had worked. The fourth item to be removed asked about whether patients would chose to undergo the same type of intervention again should it become necessary. Unfortunately, this was found to cause concern amongst participants as they felt it was suggesting that further intervention was likely. It was also decided that this aspect of satisfaction was covered in a separate item that asked whether patients would encourage others to have the same kind of treatment for their aneurysm. 
Once again, despite prompting, none of the interviewees highlighted any sources of satisfaction or dissatisfaction that had not already been covered by the questionnaire. The final version therefore contained 11 items and a single open question about any unmentioned issues.

\section{Discussion}

The focus groups and interviews provided significant new qualitative data relating to patients' experiences of AAA and AAA repair. This has identified the aspects of QoL, symptoms and treatment satisfaction that are most relevant to these patients and led to the design of three comprehensive new outcome measures.

Over and above the health status outcomes described elsewhere in the literature, patients involved in this study have identified a number of previously unrecognized QoL issues associated with AAA. These included persistent postoperative anxiety in both EVAR and OR cohorts, restrictions of activity, avoidance of sexual activity, impact on family life and loss of financial independence. Importantly, with the exception of anxiety, these newly identified themes are not addressed at all by the generic measures of health status (such as the SF36 and EQ-5D) that have commonly been used to assess patient-reported outcomes in this patient group. ${ }^{31} 32$ This emphasizes the need for the new tools - and for further study using these new tools - so that clinicians and patients can together make truly informed decisions about their care.

Patients described a wide range of symptoms and aspects of treatment that might influence their QoL. Whilst some of these symptoms may not be directly related to AAA or its repair, a conscious decision was made to retain all symptoms that had been mentioned by patients in the questionnaire until a much larger data collection has been undertaken. At that point it may be possible to remove items if there is robust evidence that they are unrelated to AAA. 
Whilst postoperative pain - particularly affecting the lower limbs - has been described previously, what was unexpected here was that persistent pain and lethargy seemed to be reported as frequently after EVAR as after OR. This differs from previous evidence suggesting that $\mathrm{OR}$ has greater long-term physical impact than EVAR. ${ }^{33}$ Whilst the data presented here are qualitative rather than quantitative, they certainly suggest that this aspect of recovery after AAA repair warrants further investigation.

The suggestion that AAA is a largely asymptomatic condition prior to intervention ${ }^{34}$ is supported by the fact that most of the patients in our cohort did not describe overt physical symptoms preoperatively. However, that is not to say that having an aneurysm had no negative impact on their QoL during this period of surveillance. In the absence of major physical symptoms, the impact of AAA on QoL appears to be centred around anxiety in the preoperative phase. Though this may have been anticipated, what was less expected was that OR and EVAR patients reported persistent anxiety after intervention. In the open-repair group, a number of patients also expressed concerns about the relative lack of follow-up and felt as though they had been left to cope alone very soon after a major operation. Indeed, patients who had undergone EVAR generally reported feeling reassured by follow-up scans, rather than seeing them as a burden or a source of anxiety. This is contrary to previous assumptions that repetitive follow-up after EVAR might cause patients to worry that they were not 'fixed' or that CT surveillance might lead to concerns about radiation exposure. ${ }^{35} 36$ It also highlights the need for more detailed study of this area, since awareness of such patient views might influence the current trend towards more rapid hospital discharge and early cessation of follow-up. At the very least it might allow clinicians to guide patients' expectations more effectively.

Guiding patients' expectations about treatment is clearly a very important part of the patient-doctor interaction, and the treatment satisfaction issues described by participants were often related to communication and the provision of information. Patients were often unclear about the nature and severity of their condition, whether they should restrict their day-to-day activity, and the 
likelihood of side-effects and complications. Though communication issues are a common source of dissatisfaction in healthcare, 37 the identification of specific deficiencies in this setting has highlighted clear targets for improvements in practice.

Though a small number of changes were made to the newly designed questionnaires during the interview phase, they were generally well understood from the outset,. They were acceptable to (and welcomed by) patients and proved to have good face- and content-validity. Items relating to the more sensitive topics little discussed in the focus groups also proved to be highly relevant and these topics therefore warrant further quantitative investigation in a larger group of patients. The QoL and symptom measures are suitable for all AAA patients investigated to date and psychometric validation (reported elsewhere) has confirmed that the Treatment Satisfaction Questionnaire has separate subscales suitable for patients pre- or post-intervention and at any of the time-points studied (i.e. whilst under preoperative surveillance and postoperatively from 6-weeks to well beyond 12 months). ${ }^{38}$

Significant efforts were made to include a representative sample of patients by involving multiple centres and OR and EVAR patients, both pre- and postintervention. However, it is recognized that the ratio of male to female participants was higher than might be expected based on the natural prevalence of the condition. This was partly because more men than women had undergone AAA repair within the preceding two years at the centres involved in the study. The number of female participants was also limited by simple logistic considerations such as whether they were readily contactable or available on the dates of the focus groups or interviews. Nonetheless, the deliberate retention of 'free text' items in the final versions of each questionnaire will ensure that patients have the opportunity to raise any issues that have not been covered within the questionnaires to date.

This paper reports the design of three new questionnaires to assess QoL (AneurysmDQoL), symptoms (AneurysmSRQ) and treatment satisfaction 


\begin{abstract}
(AneurysmTSQ) among patients with AAA. Having been developed with patient involvement at every stage, these new questionnaires are believed to be highly representative of the issues experienced by these patients. Psychometric evaluation (to be reported separately) has confirmed their structure, reliability and suitability for use in this patient group and they are now ready for wider clinical use in order to improve our understanding of the impact of AAA and AAA repair. 38
\end{abstract}

Access to the questionnaires: please visit www.healthpsychologyresearch.com

\title{
Acknowledgements
}

The authors thank the patients and the following clinicians for recruiting those patients from their NHS Trusts to take part in focus groups and interviews:

\author{
Mr David Mitchell (North Bristol NHS Trust) \\ Mr Matthew Armon and Mandy Burrows (Norfolk and Norwich University \\ Hospital NHS Trust) \\ Mr Isaac Nyamekye and Wendy Hayes (Worcestershire Acute Hospitals NHS \\ Trust) \\ Miss Jo Blundell (St George's University Hospitals NHS Foundation Trust)
}

\section{References}

1. Lucarotti M, Shaw E, Poskitt K, Heather B. The Gloucestershire Aneurysm Screening Programme: the first 2 years' experience. Eur J Vasc Endovasc 1993; 7 (4): 397-401.

2. Waton S, Johal A, Groene O, Cromwell D, Mitchell D, Loftus IM. Outcomes after elective repair of infra-renal abdominal aortic aneurysm. London: The Royal College of Surgeons of England, 2013.

3. Department of Health.Equity and Excellence: Liberating the NHS.2010. Sep 01 2013https://www.gov.uk/government/uploads/system/uploads/attach ment_data/file/213823/dh_117794.pdf

4. The Vascular Society of Great Britain and Ireland. National Abdominal Aortic Aneurysm Quality Improvement Programme Report. London, 2012. 
5. Peach G, Holt P, Loftus I, Thompson MM, Hinchliffe R. Questions remain about quality of life after abdominal aortic aneurysm repair. J Vasc Surg 2012; 56 (2): 520-527.

6. Coughlin PA, Jackson D, White AD, Bailey MA, Farrow C, Scott DJA et al. Meta-analysis of prospective trials determining the short- and mid-term effect of elective open and endovascular repair of abdominal aortic aneurysms on quality of life. Brit J Surg 2013; 100 (4): 448-455.

7. Bradley C. Importance of differentiating health status from quality of life. Lancet, 2001: 7-8.

8. Rabiee F. Focus-group interview and data analysis. P Nutr Soc 2004; 63 (4): 655-660.

9. Bradley C, Todd C, Gorton T, Symonds E, Martin A, Plowright R. The development of an individualized questionnaire measure of perceived impact of diabetes on quality of life: the ADDQoL. Qual Life Res 1999: 7991.

10. Bradley C, Speight J. Patient perceptions of diabetes and diabetes therapy: assessing quality of life. Diabetes Metab Res 2002: S64-69.

11. Bradley C. Design of a renal-dependent individualized quality of life questionnaire. Adv Perit Dial, 1997: 116-120.

12. Mitchell J, Bradley C. Design of an individualised measure of the impact of macular disease on quality of life (the MacDQoL). Qual Life Res 2004: 1163-1175.

13. Woodcock A, Bradley C, Plowright R, Ffytche T, Kennedy-Martin T, Hirsch A. The influence of diabetic retinopathy on quality of life: interviews to guide the design of a condition-specific, individualised questionnaire: the RetDQoL. Patient Educ Couns 2004: 365-383.

14. McMillan CV, Bradley C, Woodcock A, Razvi S, Weaver JU. Design of new questionnaires to measure quality of life and treatment satisfaction in hypothyroidism. Thyroid 2004: 916-925.

15. McMillan CV, Bradley C, Gibney J, Russell-Jones DL, Sönksen PH. Preliminary development of the new individualized HDQoL questionnaire measuring quality of life in adult hypopituitarism.J Eval Clin Pract 2006: 501-514.

16. Speight J, Sinclair AJ, Browne JL, Woodcock A, Bradley C. Assessing the impact of diabetes on the quality of life of older adults living in a care home: validation of the ADDQoL Senior. Diabetic Med 2013; 30 (1): 74-80.

17. Wee H-L, Tan C-E, Goh S-Y, Li S-C. Usefulness of the Audit of DiabetesDependent Quality-of-Life (ADDQoL) questionnaire in patients with diabetes in a multi-ethnic Asian country. PharmacoEconomics 2006; 24 (7): 673-682.

18. Hickey AM, Bury G, O’Boyle CA, Bradley F, O’Kelly FD, Shannon W. A new short form individual quality of life measure (SEIQoL-DW): application in a cohort of individuals with HIV/AIDS. Brit Med J 1996; 313 (7048): 2933.

19. McMillan C, Bradley C, Razvi S, Weaver J. Evaluation of new measures of the impact of hypothyroidism on quality of life and symptoms: the ThyDQoL and ThySRQ. Value Health 2008: 285-294.

20. Taylor MD HT, Ward H, McBride J, Yap I, Bradley C, . Evaluation of the hypoglycaemia symptom rating questionnaire ('HypoSRQ') and its 
relationship with hypoglycaemic episodes measured using continuous glucose monitoring [abstract]. Diabetes Technol The 2013; 15: A23-A24.

21. Bradley C, Lewis KS. Measures of psychological well-being and treatment satisfaction developed from the responses of people with tablet-treated diabetes. Diabetic Med 1990: 445-451.

22. Barendse SM, Speight J, Bradley C. The Renal Treatment Satisfaction Questionnaire (RTSQ): a measure of satisfaction with treatment for chronic kidney failure. Am J Kidney Dis 2005: 572-579.

23. Brose LS, Bradley C. Psychometric development of the retinopathy treatment satisfaction questionnaire (RetTSQ). Psychol Health Med 2009: 740-754.

24. Taback NA, Bradley C. Validation of the genital herpes treatment satisfaction questionnaire (GHerpTSQ) in status and change versions. Qual Life Res 2006: 1043-1052.

25. Woodcock A, Bradley C. Validation of the HIV treatment satisfaction questionnaire (HIVTSQ). Qual Life Res 2001: 517-531.

26. McMillan C, Bradley C, Razvi S, Weaver J. Psychometric Evaluation of a New Questionnaire Measuring Treatment Satisfaction in Hypothyroidism: The ThyTSQ. Value Health 2006; 9 (2): 132-139.

27. Letterstål A, Eldh AC, Olofsson P, Forsberg C. Patients' experience of open repair of abdominal aortic aneurysm--preoperative information, hospital care and recovery. J Clin Nurs 2010; 19 (21-22): 3112-3122.

28. Miedema BW, Schillie S, Simmons JW, Burgess SV, Liem T, Silver D. Small bowel motility and transit after aortic surgery. J Vasc Surg 2002; 36 (1): 19-24.

29. Pettersson M, Mattsson E, Bergbom I. Prospective follow-up of sexual function after elective repair of abdominal aortic aneurysms using open and endovascular techniques. J Vasc Surg 2009; 50 (3): 492-499.

30. McMillan CV, Honeyford RJ, Datta J, Madge NJH, Bradley C. The development of a new measure of quality of life for young people with diabetes mellitus: the ADDQoL-Teen. Health Qual Life Out 2004; 2: 61.

31. Rabin R, de Charro F. EQ-5D: a measure of health status from the EuroQol Group. Ann Med 2001; 33 (5): 337-343.

32. Ware JE, Sherbourne CD. The MOS 36-item short-form health survey (SF-36). I. Conceptual framework and item selection. Med Care 1992; 30 (6): 473483.

33. Prinssen M BE, Blankensteijn J D, DREAM trial participants. Quality of life endovascular and open AAA repair. Results of a randomised trial. Eur J Vasc Endovasc 2004; 27 (2): 121-127.

34. Cronenwett JL, Johnston W, Rutherford RB. Rutherford's Vascular Surgery: W.B. Saunders Company, 2010.

35. Bell PRF. Endovascular repair of abdominal aortic aneurysms. Vasc Med 2002; 7 (4): 253-255.

36. Olberg Eide TM, Romundstad P, Klepstad P, Myhre HO. Health-related quality of life in long term-survivors of thoracoabdominal aortic aneurysm repair. J Vasc Nurs 2005; 23 (3): 88-94.

37. Meryn S. Improving doctor-patient communication. Not an option, but a necessity. Brit Med J 1998; 316 (7149): 1922.

38. Romaine J, Peach G, Thompson MM, Hinchliffe RJ, Bradley C. Psychometric development of three new condition-specific questionnaires to measure 
quality of life (Aneurysm-DQoL), symptoms (Aneurysm-SRQ) and treatment satisfaction (Aneurysm-TSQ) of individuals with abdominal aortic aneurysms [abstract]. Qual Life Res 2015; 24 (1): 41-42. 


\begin{tabular}{|c|c|c|c|c|c|}
\hline \multirow[t]{2}{*}{5 (a) } & \multicolumn{5}{|c|}{ If I had never had an aneurysm, physically I could do: } \\
\hline & $\begin{array}{c}\square-3 \\
\text { very much more }\end{array}$ & $\underset{\text { much more }}{\square-2}$ & $\begin{array}{c}\square-1 \\
\text { a little more }\end{array}$ & $\begin{array}{c}\square 0 \\
\text { the same }\end{array}$ & $\square_{\text {less }}+1$ \\
\hline (b) & $\begin{array}{c}\text { For me, how muc } \\
\square+3 \\
\text { very important }\end{array}$ & I can do phy & ly is: & ortant & $\begin{array}{c}\square 0 \\
\text { not at all importa }\end{array}$ \\
\hline
\end{tabular}

Fig 1 - Example of question format and scoring for the Aneurysm-Dependent Quality of Life Questionnaire (AneurysmDQoL) (scoring shown for information only - not usually visible). $254 \times 190 \mathrm{~mm}(72 \times 72 \mathrm{DPI})$ 


\begin{tabular}{|c|l|}
\hline 1 (a) & Have you felt unusually tired or lethargic in recent weeks? \\
& $\begin{array}{l}\text { No } \square \text { If no, go to next symptom } \\
\text { Yes } \square \text { If yes, complete (b) }\end{array}$ \\
\hline (b) & If yes, how much has this bothered you? \\
& $\square$ \\
not at all
\end{tabular}

Fig 2 - Example item from the Aneurysm Symptom Rating Questionnaire (AneurysmSRQ). $254 \times 190 \mathrm{~mm}(72 \times 72$ DPI $)$ 
5. How satisfied are you with feedback about scan results?

$\begin{array}{lllllllll}\text { very satisfied } & 6 & 5 & 4 & 3 & 2 & 1 & 0 & \text { very dissatisfied }\end{array}$

Fig. 3 - Example item from the Aneurysm Treatment Satisfaction Questionnaire (AneurysmTSQ). $254 \times 190 \mathrm{~mm}(72 \times 72 \mathrm{DPI})$ 
Table 1 - Patient/group demographics

\begin{tabular}{|c|c|c|c|}
\hline & OR & EVAR & Surveillance \\
\hline Number of focus groups & 2 & 6 & 1 \\
\hline $\begin{array}{c}\text { Number of focus group } \\
\text { participants (male/female) }\end{array}$ & $8(6 / 2)$ & $29(28 / 1)$ & $4(4 / 0)$ \\
\hline $\begin{array}{c}\text { Number of interviewees } \\
\text { (male/female) }\end{array}$ & $3(3 / 0)$ & $6(6 / 0)$ & $4(4 / 0)$ \\
\hline $\begin{array}{c}\text { Mean age yrs (range) } \\
(65.3-86.3)\end{array}$ & $\begin{array}{c}72.9 \\
(61.4-88.2)\end{array}$ & $\begin{array}{c}73.7 \\
(64.9-84.2)\end{array}$ \\
\hline $\begin{array}{c}\text { Mean time since } \\
\text { intervention (months) } \\
\text { (range) }\end{array}$ & $8.0(3-20)$ & $5.7(2-13)$ & $\mathrm{n} / \mathrm{a}$ \\
\hline
\end{tabular}


Table 2 - Aspects of QoL, symptoms and treatment satisfaction identified during focus groups

\begin{tabular}{|c|c|c|}
\hline Outcome & $\begin{array}{c}\text { No. of } \\
\text { groups } \\
\text { mentioning }\end{array}$ & Example quote \\
\hline \multicolumn{3}{|c|}{ Quality of Life } \\
\hline $\begin{array}{cl}\text { Preoperative anxiety } \\
- & \text { Fear of rupture } \\
- & \text { Increasing anxiety as aneurysm grew } \\
- & \text { Waiting indefinitely for intervention } \\
- & \text { Anxiety about intervention itself } \\
\end{array}$ & $\begin{array}{l}8 \\
8 \\
5 \\
2 \\
2\end{array}$ & $\begin{array}{l}\text { - 'what QoL could I have with a time-bomb } \\
\text { inside of me' } \\
\text { - I waited } 18 \text { months and it was getting } \\
\text { bigger and bigger and I was on edge waiting } \\
\text { for the results } \\
\text { - 'I didn't worry at first, but when it was } \\
\text { said that action was needed I got worried' }\end{array}$ \\
\hline Postoperative anxiety & 4 & $\begin{array}{l}\text { 'once you have one thing that was } \\
\text { completely symptomless you wonder what } \\
\text { else you might have wrong with you' }\end{array}$ \\
\hline Restrictions of activity & 4 & 'I was terrified to do anything' \\
\hline Impact on work & 3 & $\begin{array}{l}\text { 'I got through all the tests to be a truck } \\
\text { driver and they sent me for all these tests } \\
\text { and then doc said you won't get the job, } \\
\text { you've got an aneurysm' }\end{array}$ \\
\hline Relief of anxiety postop & 3 & $\begin{array}{l}\text { 'When I had the op it felt like someone had } \\
\text { defused the bomb' }\end{array}$ \\
\hline Impact on social life & 1 & $\begin{array}{l}\text { 'I find it overwhelming in a crowded room } \\
\text { since the operation. Prior to that you } \\
\text { couldn't keep me out of a crowded pub.' } \\
\text { 'I don't feel sociable' }\end{array}$ \\
\hline Financial implications & 1 & $\begin{array}{l}\text { Commercial driver: 'I'm now restricted to a } \\
1 \text { year [driving] licence. }\end{array}$ \\
\hline Loss of independence & 1 & 'I don't go out so much since the operation' \\
\hline Not returned to 'normal' & 1 & $\begin{array}{l}\text { 'Nothing was the same [after the operation] } \\
\text { and nothing still is' }\end{array}$ \\
\hline Not prepared for severity & 1 & '...it didn't feel like a serious operation' \\
\hline Increased awareness of own mortality & 1 & $\begin{array}{l}\text { '[I had a] sense of mortality...You're going } \\
\text { to die one day' }\end{array}$ \\
\hline Positive impact on relationships & 1 & $\begin{array}{l}\text { 'Quality of life, in some respects, has } \\
\text { improved. I spend more time interacting } \\
\text { with family and value each day more than } \\
\text { before.' }\end{array}$ \\
\hline \multicolumn{3}{|c|}{ Symptoms } \\
\hline Lethargy & 7 & 'Had no get up and go' \\
\hline Leg pain & 7 & 'Aches in legs all the time now' \\
\hline Back pain & 5 & 'I get lower back pain' \\
\hline Abdominal pain & 4 & $\begin{array}{l}\text { 'Had a routine examination (scan) for } \\
\text { stomach pains and found AAA' }\end{array}$ \\
\hline Buttock pain & 4 & $\begin{array}{l}\text { 'I had some pain in my left buttock for some } \\
\text { time' }\end{array}$ \\
\hline Calf pain & 4 & $\begin{array}{l}\text { 'I get aching in the legs sometimes - claves } \\
\text { below the knees' }\end{array}$ \\
\hline Low mood & 4 & $\begin{array}{l}\text { 'I got so depressed I had to have anti- } \\
\text { depressants afterwards' }\end{array}$ \\
\hline Weight loss & 4 & 'I lost a lot of weight...I've lost a stone' \\
\hline Bruising & 3 & $\begin{array}{l}\text { 'I had a lot of bruising after - black and blue } \\
\text { to the knees' }\end{array}$ \\
\hline Leg swelling & 3 & $\begin{array}{l}\text { 'had a small amount of swelling and the } \\
\text { nurse said it would go down' }\end{array}$ \\
\hline Leg numbness & 3 & 'I had this strange numbness' \\
\hline Decreased activity & 2 & $\begin{array}{l}\text { 'Physical activity is down - perhaps because } \\
\text { I'm thinking I shouldn't overdo it.' }\end{array}$ \\
\hline
\end{tabular}




\begin{tabular}{|c|c|c|}
\hline General weakness & 2 & 'I feel a lot weaker to what I used to' \\
\hline Profuse sweating & 2 & 'boiling hot, then sweating, then chills' \\
\hline Poor appetite & 2 & $\begin{array}{l}\text { 'I would fantasize about food but if it was } \\
\text { put in front of me I thought oh no' }\end{array}$ \\
\hline Poor balance & 1 & $\begin{array}{l}\text { 'The legs worked but felt different - wobbly } \\
\text { like I was drunk.' }\end{array}$ \\
\hline Leg weakness & 1 & $\begin{array}{l}\text { 'The right leg is not as strong as the left. } \\
\text { That's new since the op' }\end{array}$ \\
\hline Leg heaviness & 1 & $\begin{array}{l}\text { '...my right leg was really heavy, like a lump } \\
\text { of lead' }\end{array}$ \\
\hline Poor cognitive function & 1 & $\begin{array}{l}\text { 'I put Christmas cards there and list there } \\
\text { and couldn't put the two together' }\end{array}$ \\
\hline Panic attacks & 1 & $\begin{array}{l}\text { 'I had panic attacks for a couple of weeks - } \\
\text { and that's not something I've ever had } \\
\text { before.' }\end{array}$ \\
\hline Hallucinations & 1 & $\begin{array}{l}\text { 'I had hallucinations I had been taken by a } \\
\text { group and they were going to kill me.' }\end{array}$ \\
\hline Changes in bowel function & 1 & $\begin{array}{l}\text { 'I went to my doctor because I had... a lot of } \\
\text { flatulence that was causing discomfort.' }\end{array}$ \\
\hline Changes in urinary function & 1 & $\begin{array}{l}\text { '...the next day I had waterwork problems } \\
\text { and still have' }\end{array}$ \\
\hline Wound problems & 1 & $\begin{array}{l}\text { '...wound from second op bled and bled and } \\
\text { oozed congealed blood.' }\end{array}$ \\
\hline \multicolumn{3}{|c|}{ Treatment satisfaction } \\
\hline Unclear about risks (e.g. air travel) & 6 & $\begin{array}{l}\text { 'No one said what you can do and what you } \\
\text { can't.' }\end{array}$ \\
\hline No choice in type of operation & 6 & '...the stent option wasn't mentioned.' \\
\hline Not clear how serious AAA was & 5 & $\begin{array}{l}\text { 'No mention of taking it easy until after the } \\
\text { op...that was the first I knew how serious it } \\
\text { was.' }\end{array}$ \\
\hline Scans reassuring NOT a burden & 5 & $\begin{array}{l}\text { 'It's a pleasure coming here and being told } \\
\text { you're OK.' }\end{array}$ \\
\hline Complications sometimes confusing & 3 & $\begin{array}{l}\text { '...was told I had a bent limb. I didn't } \\
\text { understand..' }\end{array}$ \\
\hline Insufficient time to discuss diagnosis & 3 & 'There wasn't a lot of time to ask questions.' \\
\hline Familial risks unclear & 3 & $\begin{array}{l}\text { '[The information leaflet] didn't deal with } \\
\text { the risks of having an aneurysm - risk } \\
\text { factors, genetics, smoking.' }\end{array}$ \\
\hline Felt unready to go home & 3 & $\begin{array}{l}\text { 'I didn't feel ready to go home...I was more } \\
\text { knackered than I expected to be.' }\end{array}$ \\
\hline Little contact with surgeon & 2 & $\begin{array}{l}\text { 'Although you get the scan you don't } \\
\text { automatically get [to see] the consultant.' }\end{array}$ \\
\hline No warning about side-effects & 2 & $\begin{array}{l}\text { 'There was a lack of information about any } \\
\text { likely adverse outcomes of the op.' } \\
\text { 'I had no appreciation of what I would feel } \\
\text { like after this operation. ' }\end{array}$ \\
\hline Poor understanding of AAA & 2 & $\begin{array}{l}\text { 'If the AAA bursts the chances of surviving } \\
\text { are pretty slim - but that is something I } \\
\text { found out from the web, not from here.' } \\
\text { 'How do they do it? Where does the blood } \\
\text { go? I didn't really get an answer I } \\
\text { understood.' }\end{array}$ \\
\hline Little time for consent & 2 & $\begin{array}{l}\text { 'It would have been better to have had the } \\
\text { consent form sooner.' }\end{array}$ \\
\hline Insufficient feedback about scans & 2 & $\begin{array}{l}\text { '...when they scan you they don't tell you } \\
\text { [the results] - the operator of the scanner. } \\
\text { You have to make an appointment.' }\end{array}$ \\
\hline Hospital stay too long & 1 & $\begin{array}{l}\text { 'They kept me in for a day longer than I felt } \\
\text { was needed' }\end{array}$ \\
\hline Postop wound management unclear & 1 & $\begin{array}{l}\text { 'I wasn't sure when to take the dressings } \\
\text { off.' } \\
\text { 'Some hospitals don't tell you what to do } \\
\text { but say they will write to the GP and }\end{array}$ \\
\hline
\end{tabular}




\begin{tabular}{|l|c|l|}
\hline & & patients can talk to them.' \\
\hline Insufficient follow-up / support & 1 & $\begin{array}{l}\text { '[l] objected to being cut out of the } \\
\text { physiotherapists list without seeing me.' }\end{array}$ \\
\hline Local f/u would be preferable & 1 & $\begin{array}{l}\text { 'The only thing was can we have scans at } \\
\text { [local hospital] because it's so much closer } \\
\text { to home.' }\end{array}$ \\
\hline Worried about radiation in theatre & 1 & $\begin{array}{l}\text { '...worried...how much radiation I was going } \\
\text { to get' }\end{array}$ \\
\hline
\end{tabular}




\section{Appendix 1 - Domains covered in the final development versions of the 3 new tools:}

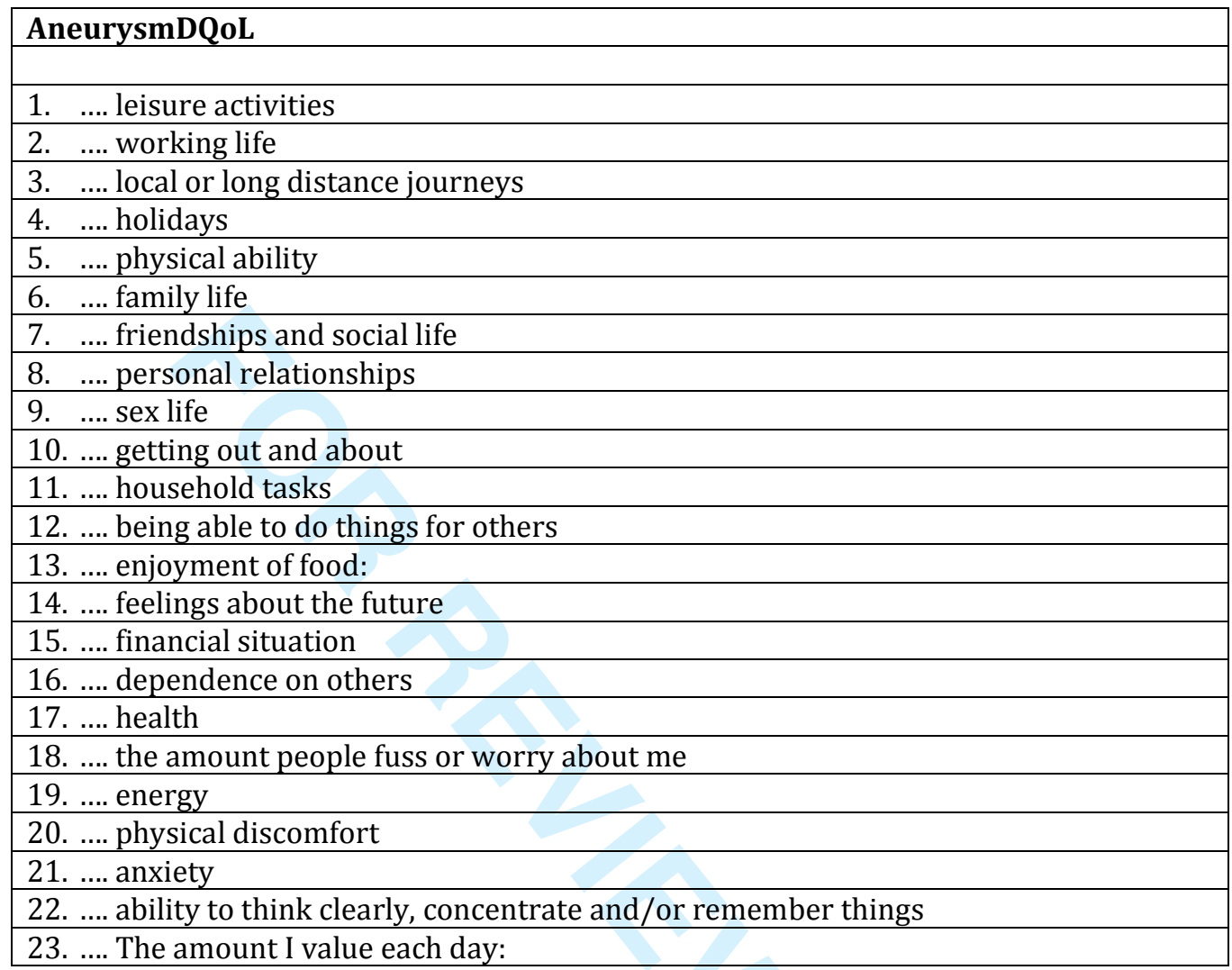

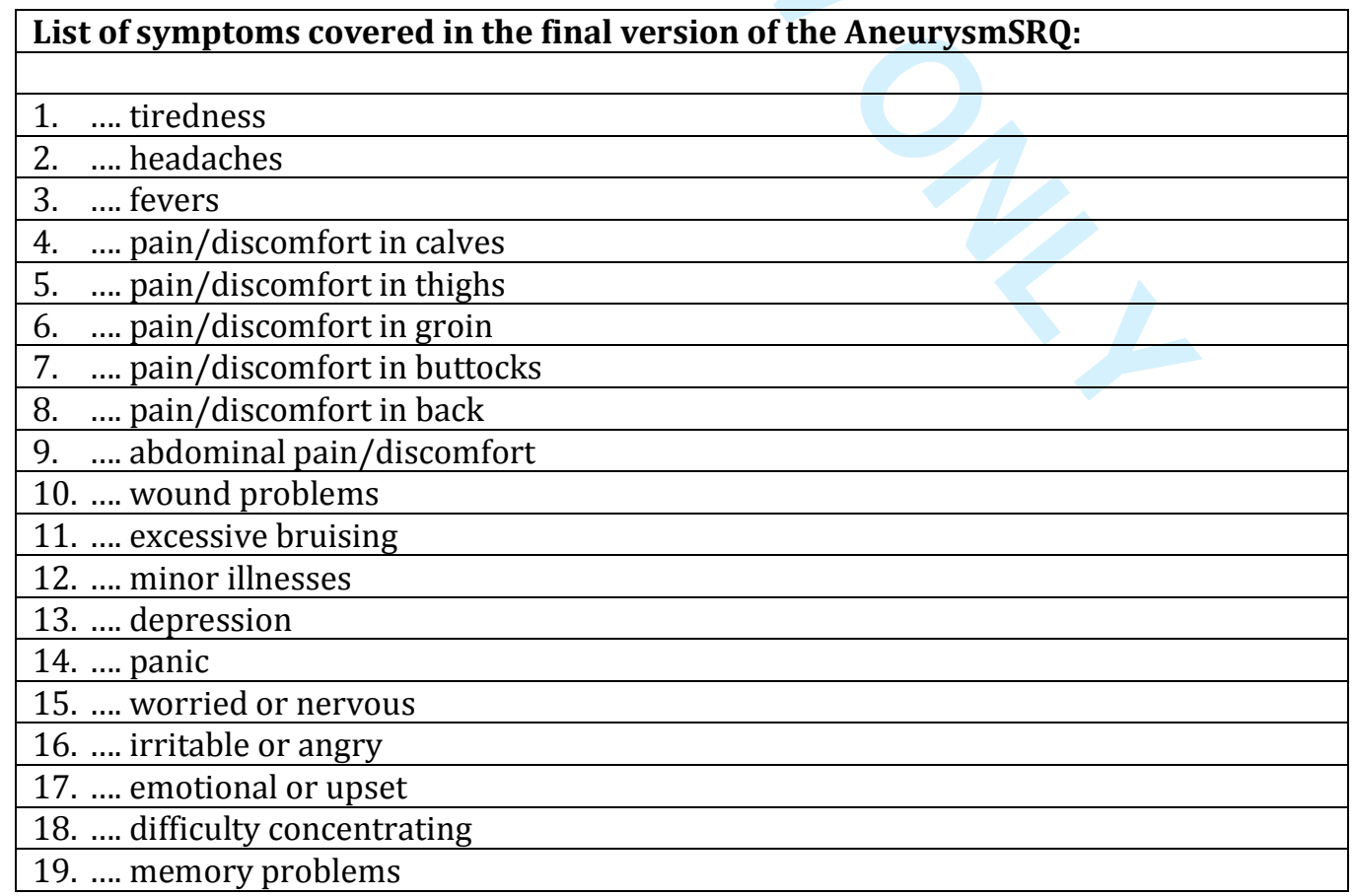




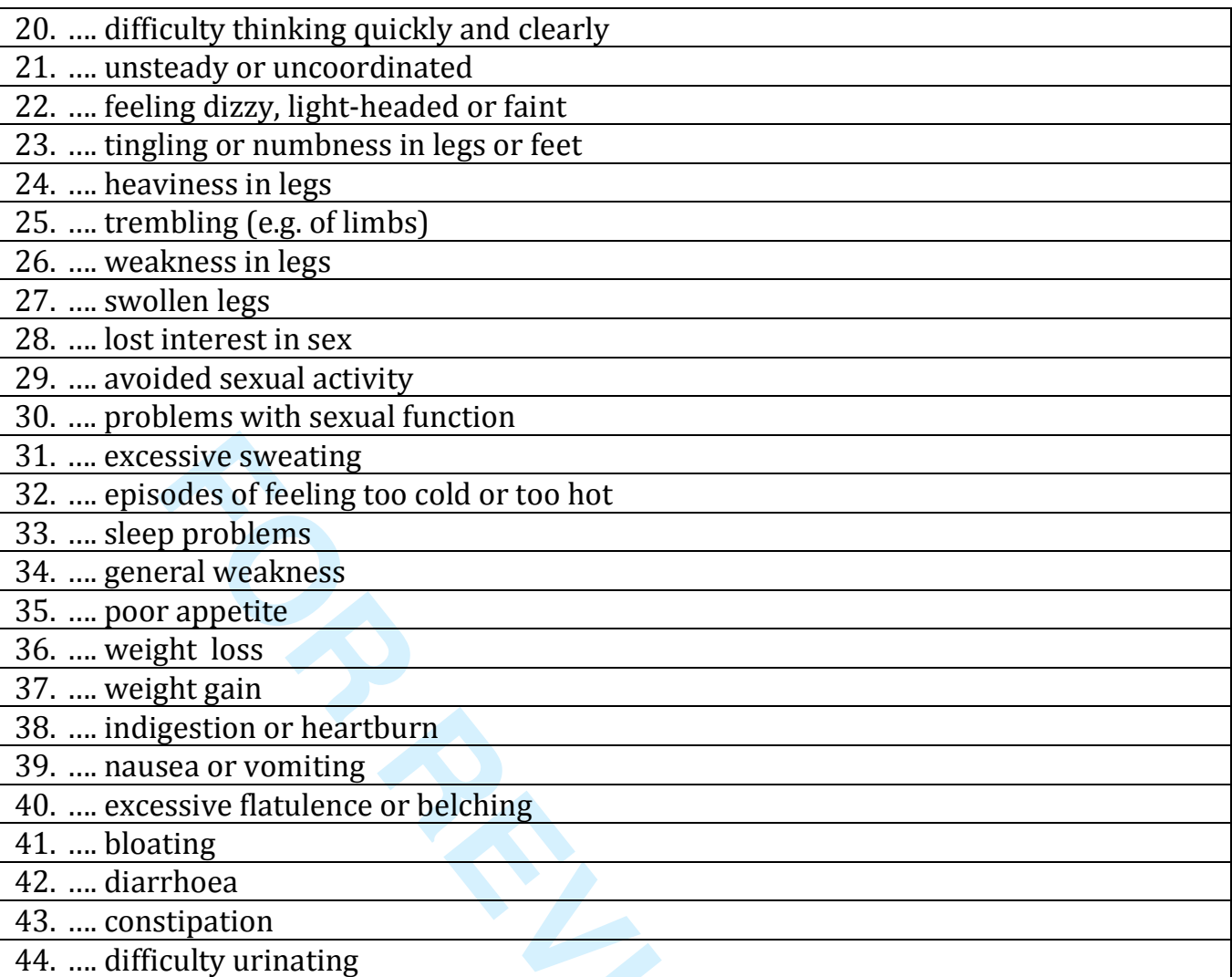

\section{Aspects of treatment covered in the final version of the AneurysmTSQ:}

1. .... aneurysm treatment (including monitoring)

2. .... convenience of treatment (including monitoring)

3. .... bothered by any discomfort or pain

4. .... information provided

5. ... feedback about scan results

6. .... amount of support from nurses, doctors and other clinical staff

7. .... understanding of the treatment (including any operation/monitoring)

8. .... length of stay in hospital

9. .... side effects of the treatment

10..... post-operative follow-up

$11 . . .$. likely to encourage others to have the same kind of treatment 


\section{AneurysmDQoL (Aneurysm-Dependent Quality of Life)}

This questionnaire asks about your quality of life - in other words how good or bad you feel your life to be.

Please put an " $X$ " in the box that best indicates your response for each item.

What we would like to know is how you feel about your life now.

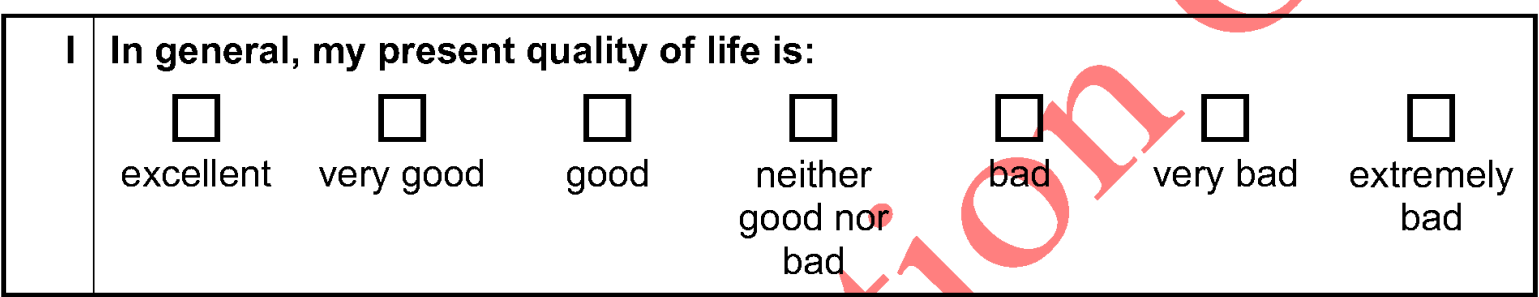

Now we would like to know how your quality of life is affected by having had an aortic aneurysm, its treatment (including monitoring) and/or any side effects you may have.

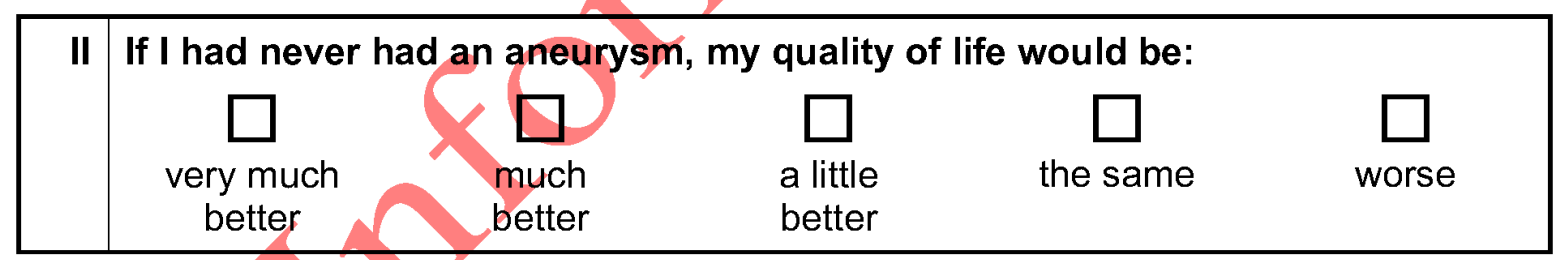


Please respond to the more specific questions on the following pages. For each aspect of life described, you will find two parts:

For Part (a): put an " $X$ " in one box to show how your aneurysm affects this aspect of your life;

For Part (b): put an " $X$ " in one box to show how important this aspect of your life is to your quality of life.

1 (a) If I had never had an aneurysm, I would enjoy my leisure activities:<smiles>[TeH]</smiles>

very much more

much more

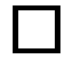

a little more

the same

less

(b) My leisure activities are:
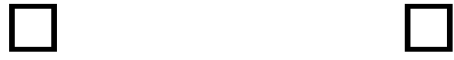

important

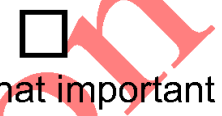
not at all important

2 Are you currently working, looking for work or would you like to work?

Yes $\square$ If yes, complete (a) and (b).

No $\square$ If no, go straight to 3 (a).

(a) If I had never had an aneurysm, my working life would be:

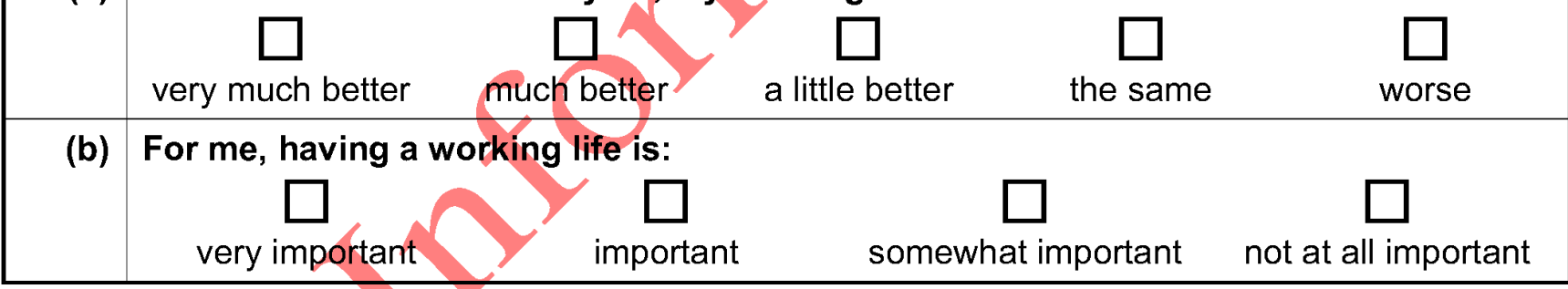

3 (a) If I had never had an aneurysm, local or long distance journeys would be:
very much easier
much easier
a little easier
the same
more difficult

(b) For me, local or long distance journeys are:
very important
important
somewhat important
not at all important 


\begin{tabular}{|l|l|}
\hline 4 & $\begin{array}{l}\text { Do you ever go on holiday or want to go on holiday? } \\
\text { Yes } \square \text { If yes, complete (a) and (b). } \\
\text { No } \square \text { If no, go straight to } 5 \text { (a). }\end{array}$ \\
\hline (a) & $\begin{array}{l}\text { If I had never had an aneurysm, my holidays would be: } \\
\text { very much better much better }\end{array}$ \\
\hline (b) & $\begin{array}{l}\text { For me, holidays are: } \\
\text { very important }\end{array}$
\end{tabular}
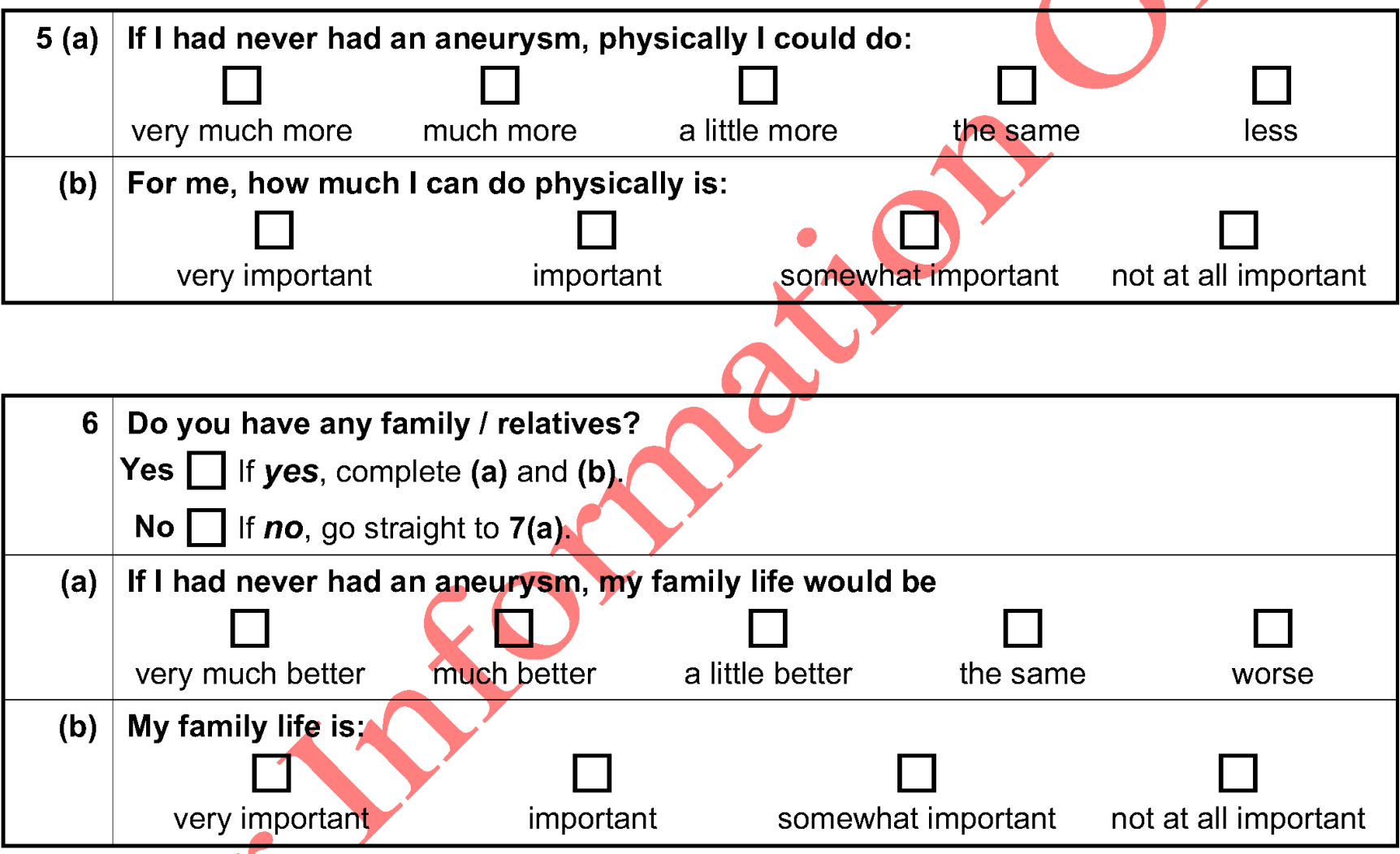

7 (a) If I had never had an aneurysm, my friendships and social life would be:

\begin{tabular}{|c|c|c|c|c|c|}
\hline & very much better & much better & a little better & the same & worse \\
\hline (b) & \multicolumn{5}{|c|}{ My friendships and social life are: } \\
\hline
\end{tabular}


12 (a) If I had never had an aneurysm, I could do things for others as I wish:

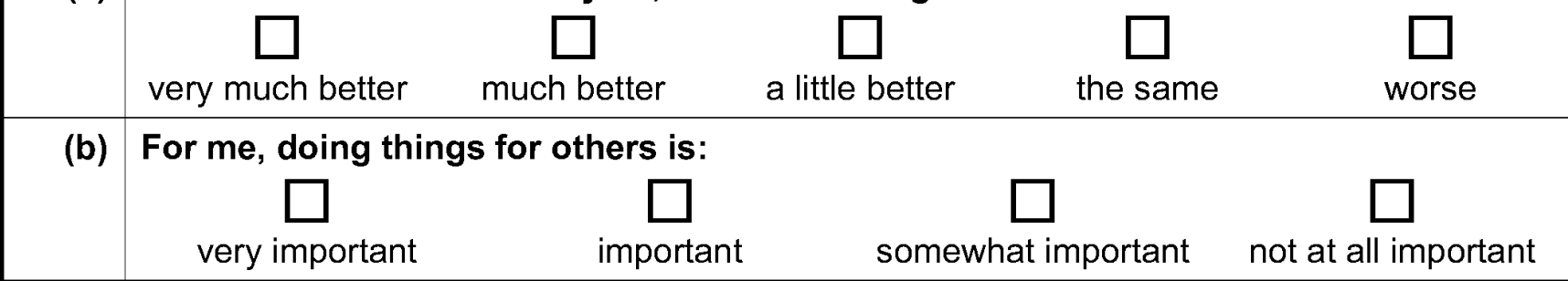
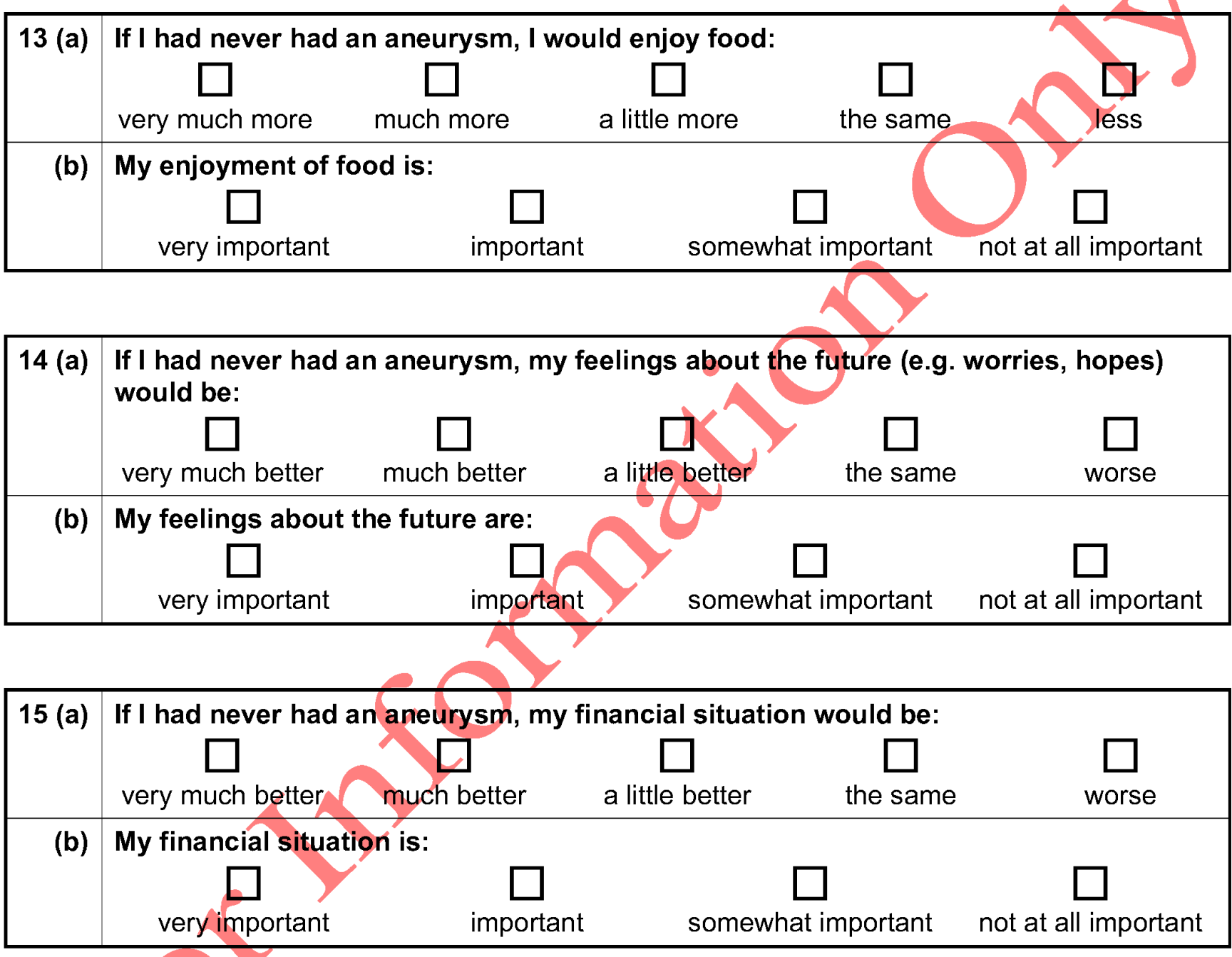

16 (a) If I had never had an aneurysm, I would have to depend on others (when I do not want to):

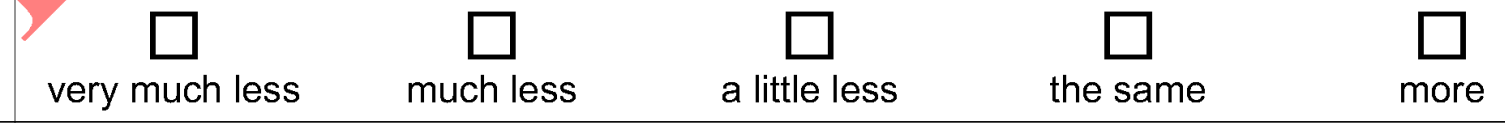

(b) For me, not having to depend on others is:

very important $\quad \square \quad$ somewhat important not at all important



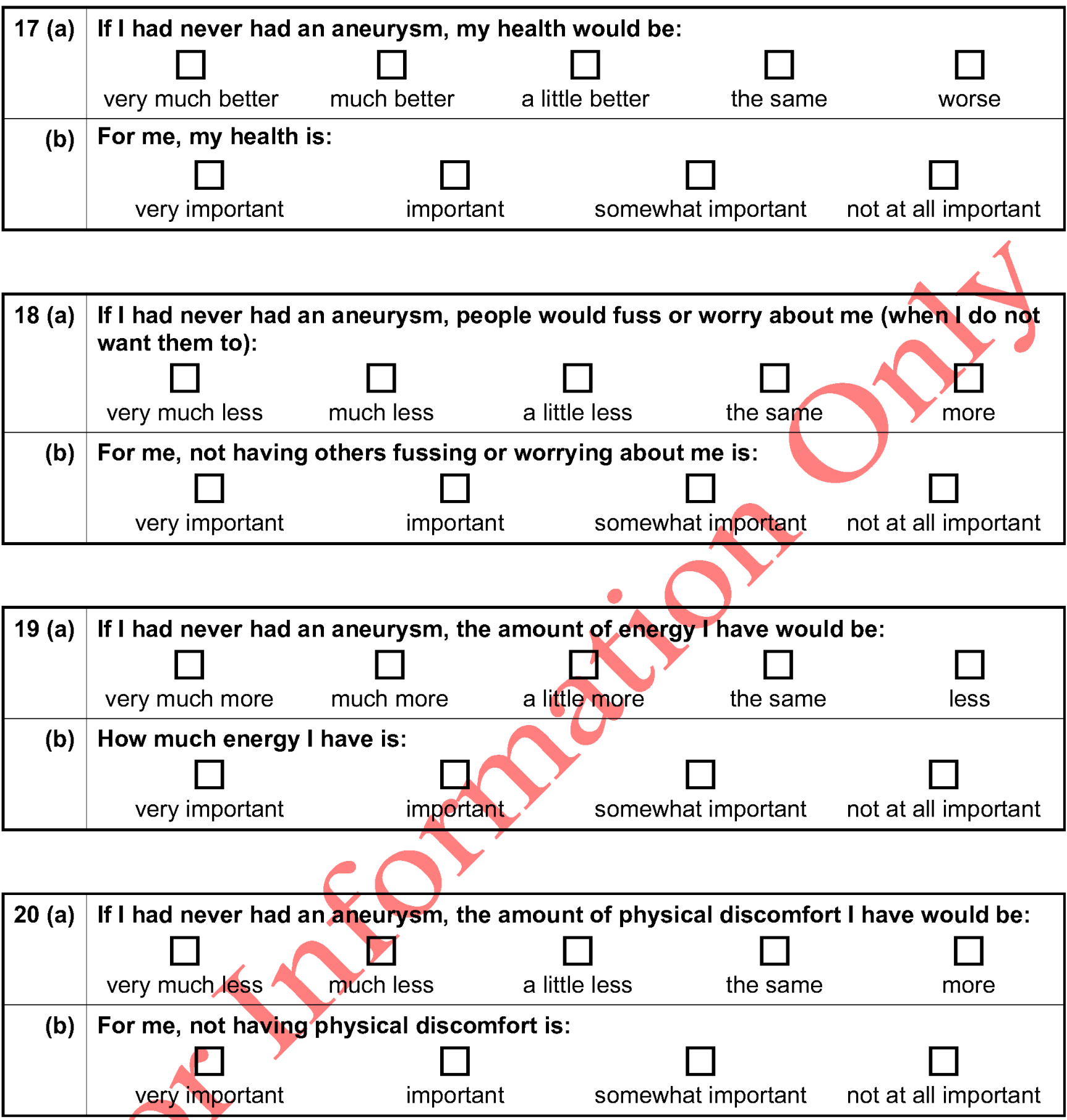

21 (a) If I had never had an aneurysm, the amount of anxiety I have would be:

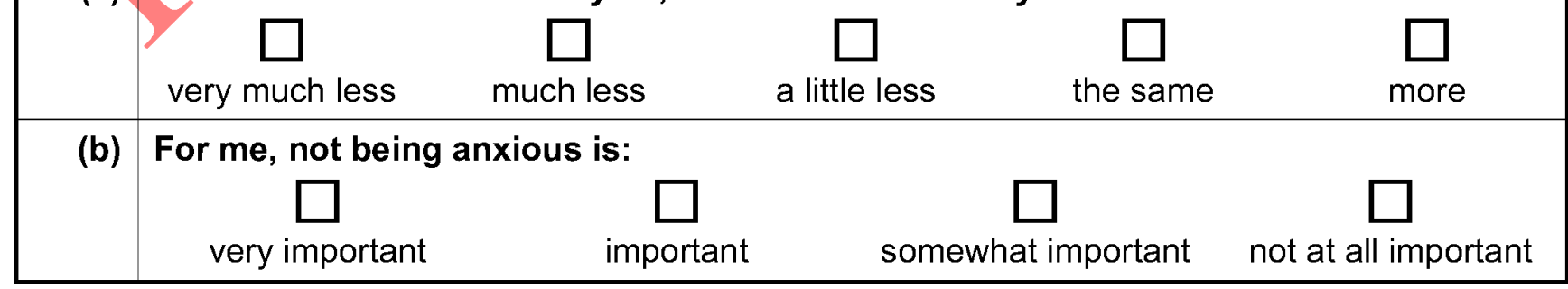


22 (a) If I had never had an aneurysm, my ability to think clearly, concentrate and/or remember things would be:

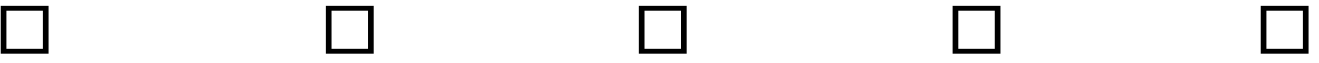

very much better much better a little better the same worse

(b) For me, my ability to think/concentrate/remember is:

very important important somewhat important not at all important

If there are any other ways in which your quality of life is affected by having had an aortic aneurysm, please say what they are below:

Thank you for completing this questionnaire. 


\section{AneurysmSRQ (Aneurysm Symptom Rating Questionnaire)}

This questionnaire asks you about symptoms that can be associated with aortic aneurysm and its treatment (including monitoring and any operation/medication). You might have experienced some of these symptoms in recent weeks (i.e. about 4 weeks).

Each question has two parts:

for part (a) put an "X" in the box $\square$ to indicate if you have had the symptom in recent weeks, regardless of the cause;

for part (b) put an " $X$ " in the box $\square$ to indicate how much the symptom has bothered you. ONLY answer part (b) if you answered "yes" to part (a).

1 (a) Have you felt unusually tired or lethargic in recent weeks?

No $\square$ If no, go to next symptom

Yes $\square$ If yes, complete (b)

(b) If yes, how much has this bothered you?

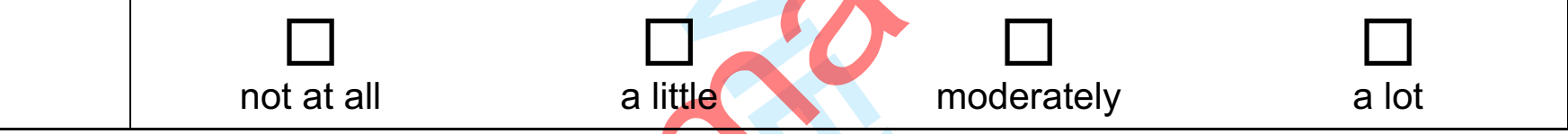

2 (a) Have you had headaches in recent weeks?

No $\square$ If no, go to next symptom

Yes $\square$ If yes, complete (b)

(b) If yes, how much has this bothered you?

not at all
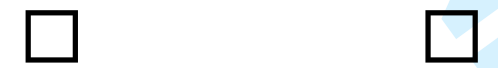

moderately

a lot

3 (a) Have you felt feverish in recent weeks?

No $\square$ If no, go to next symptom

Yes $\square$ If yes, complete (b)

(b) If yes, how much has this bothered you?
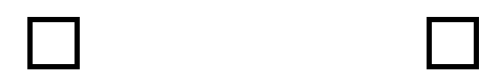

not at all

a little

moderately

a lot 


\begin{tabular}{|l|l|}
\hline 4 (a) & Have you had pain/discomfort in your calves in recent weeks? \\
& No $\square$ If no, go to next symptom \\
& Yes $\square$ If yes, complete (b) \\
\hline (b) & If yes, how much has this bothered you? \\
& \\
& not at all
\end{tabular}

\begin{tabular}{|l|l|}
\hline $\mathbf{5}$ (a) & Have you had pain/discomfort in your thighs in recent weeks? \\
& No $\square$ If no, go to next symptom \\
& Yes $\square$ If yes, complete (b) \\
\hline (b) & If yes, how much has this bothered you? \\
& not at all
\end{tabular}

\begin{tabular}{|l|l|l|}
\hline 6 (a) & Have you had pain/discomfort in your groin in recent weeks? \\
& No $\square$ If no, go to next symptom \\
& Yes $\square$ If yes, complete (b) \\
\hline (b) & If yes, how much has this bothered you? \\
& not at all
\end{tabular}

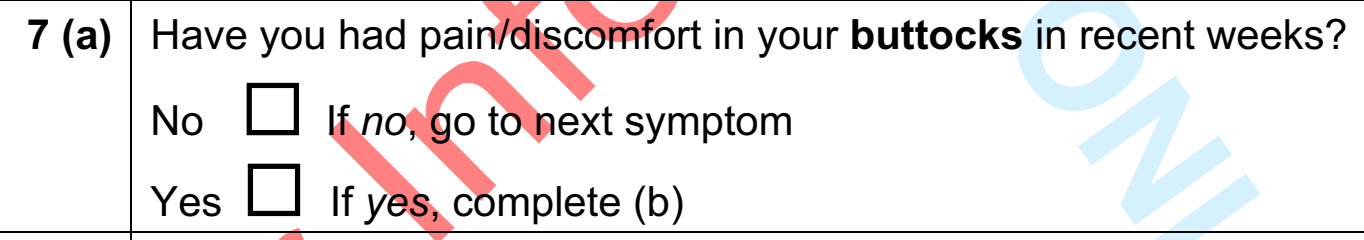

(b) If yes, how much has this bothered you?

\begin{tabular}{|l|l|}
\hline 8 (a) & Have you had pain/discomfort in your back in recent weeks? \\
& No $\square$ If no, go to next symptom \\
& Yes $\square$ If yes, complete (b) \\
\hline (b) & If yes, how much has this bothered you? \\
& \\
not at all
\end{tabular}




\begin{tabular}{|l|l|}
\hline 9 (a) & Have you had abdominal pain/discomfort in recent weeks? \\
& No $\square$ If no, go to next symptom \\
& Yes $\square$ If yes, complete (b) \\
\hline (b) & If yes, how much has this bothered you? \\
& \\
& not at all
\end{tabular}

\begin{tabular}{|c|l|}
\hline 10 (a) & Have you had any wound problem (e.g. infection or bleeding) in recent weeks? \\
& No $\square$ If no, go to next symptom \\
& Yes $\square$ If yes, complete (b) \\
& N/A $\square$ If not applicable (N/A), go to next symptom \\
\hline (b) & If yes, how much has this bothered you? \\
& not at all \\
&
\end{tabular}

11 (a) Have you had excessive bruising in recent weeks?

No $\square$ If no, go to next symptom

Yes $\square$ If yes, complete (b)

(b) If yes, how much has this bothered you?

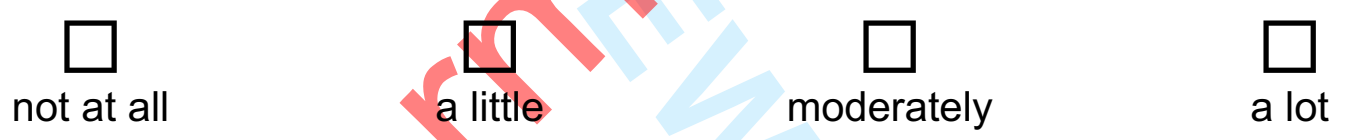

12 (a) Have you had one or more minor illnesses (e.g. a cold, sore throat, urinary tract infection) in recent weeks?

No $\square$ If no, go to next symptom

Yes $\square$ If yes, complete (b)

(b) If yes, how much has this bothered you?

13 (a) Have you felt depressed or low in recent weeks?

No $\square$ If no, go to next symptom

Yes $\square$ If yes, complete (b)

(b) If yes, how much has this bothered you?

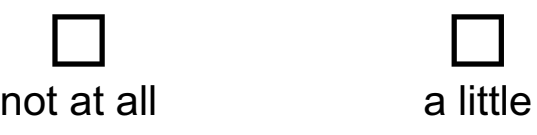




\begin{tabular}{|l|l|}
\hline 14 (a) & Have you had feelings of panic in recent weeks? \\
& No $\square$ If no, go to next symptom \\
& Yes $\square$ If yes, complete (b) \\
\hline (b) & If yes, how much has this bothered you? \\
& \\
&
\end{tabular}

\begin{tabular}{|c|l|}
\hline 15 (a) & Have you felt worried or nervous in recent weeks? \\
& No $\square$ If no, go to next symptom \\
& Yes $\square$ If yes, complete (b) \\
\hline (b) & If yes, how much has this bothered you? \\
& $\square$ \\
& not at all
\end{tabular}

\begin{tabular}{|l|l|}
\hline 16 (a) & Have you felt unusually irritable or angry in recent weeks? \\
& No $\square$ If no, go to next symptom \\
& Yes $\square$ If yes, complete (b) \\
\hline (b) & If yes, how much has this bothered you? \\
& \\
& not at all
\end{tabular}

\begin{tabular}{|l|l|}
\hline 17 (a) & Have you felt unusually emotional or easily upset in recent weeks? \\
& No $\square$ If no, go to next symptom \\
& Yes $\square$ If yes, complete (b) \\
(b) & If yes, how much has this bothered you? \\
& $\square$
\end{tabular}

\begin{tabular}{|l|l|l|}
\hline 18 (a) & Have you had difficulty concentrating in recent weeks? \\
& No $\square$ If no, go to next symptom \\
& Yes $\square$ If yes, complete (b) \\
\hline (b) & If yes, how much has this bothered you? \\
& \\
not at all & a little
\end{tabular}


19 (a) Have you had memory problems in recent weeks?

No $\square$ If no, go to next symptom

Yes $\square$ If yes, complete (b)

(b) If yes, how much has this bothered you?

not at all

a little

moderately

a lot

20 (a) Have you had difficulty thinking quickly and clearly in recent weeks?

No $\square$ If no, go to next symptom

Yes $\square$ If yes, complete (b)

(b) If yes, how much has this bothered you?

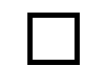

not at all

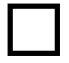

a little

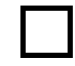

moderately

a lot

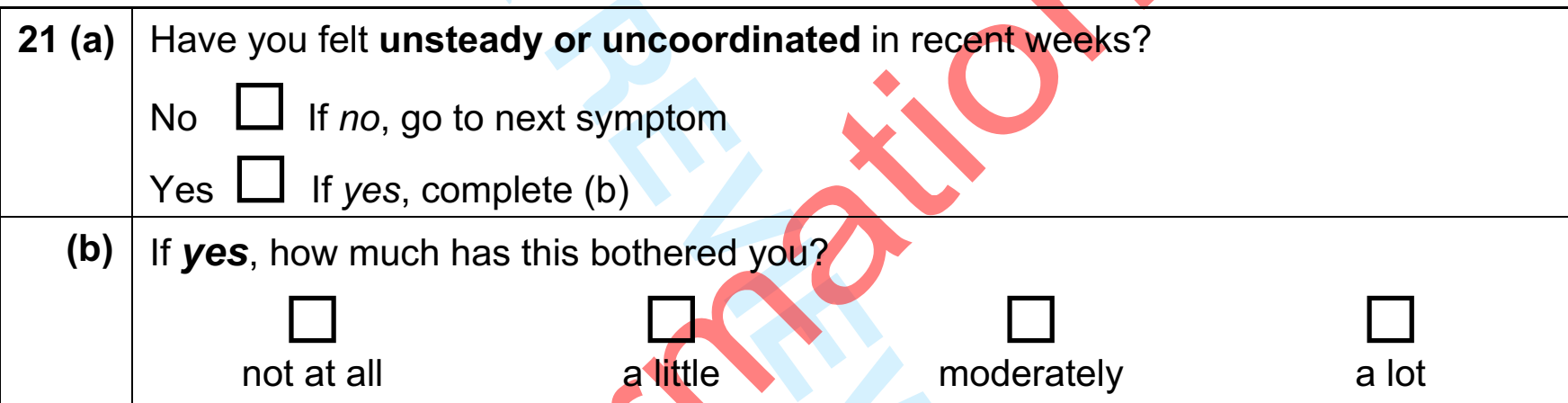

22 (a) Have you felt dizzy, light-headed or faint in recent weeks?

No $\square$ If no, go to next symptom

Yes $\square$ if yes, complete (b)

(b) If yes, how much has this bothered you?

not at all

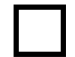

a little

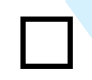

moderately

a lot 


\begin{tabular}{|l|l|}
\hline 24 (a) & Have you had heaviness in your leg(s) in recent weeks? \\
& No $\square$ If no, go to next symptom \\
& Yes $\square$ If yes, complete (b) \\
\hline (b) & If yes, how much has this bothered you? \\
& \\
not at all
\end{tabular}

\begin{tabular}{|l|l|}
\hline 25 (a) & Have you had trembling (e.g. of limbs) in recent weeks? \\
& No $\square$ If no, go to next symptom \\
& Yes $\square$ If yes, complete (b) \\
\hline (b) & If yes, how much has this bothered you? \\
& \\
& not at all
\end{tabular}

\begin{tabular}{|c|c|}
\hline 26 (a) & $\begin{array}{l}\text { Have you had weakness in your leg(s) in recent weeks? } \\
\text { No } \square \text { If no, go to next symptom } \\
\text { Yes } \square \text { If yes, complete (b) }\end{array}$ \\
\hline (b) & $\begin{array}{c}\text { If yes, how much has this bothere } \\
\text { not at all a little }\end{array}$ \\
\hline
\end{tabular}

\begin{tabular}{|c|l}
27 (a) & Have you had swollen legs in recent weeks? \\
& No $\square$ If no, go to next symptom \\
& Yes $\square$ If yes, complete (b) \\
\hline (b) & If yes, how much has this bothered you? \\
& \\
& not at all
\end{tabular}

28 (a) Have you lost interest in sex in recent weeks?

No $\square$ If no, go to next symptom

Yes $\square$ If yes, complete (b)

N/A $\square$ If not applicable (N/A), go to next symptom

(b) If yes, how much has this bothered you?

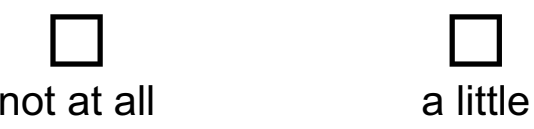


29 (a) Have you avoided sexual activity due to worry about your aneurysm / aneurysm repair?

No $\square$ If no, go to next symptom

Yes $\square$ If yes, complete (b)

N/A $\square$ If not applicable (N/A), go to next symptom

(b) If yes, how much has this bothered you?

not at all

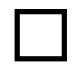

a little moderately

a lot

30 (a) Have you had any problem with sexual function in recent weeks?

No $\square$ If no, go to next symptom

Yes $\square$ If yes, complete (b)

N/A $\square$ If not applicable (N/A), go to next symptom

(b) If yes, how much has this bothered you?

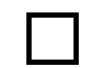

not at all

a little

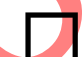

moderately

a lot

32 (a) Have you had episodes of feeling too cold or feeling too hot in recent weeks?

No $\square$ If no, go to next symptom

Yes $\square$ If yes, complete (b)

(b) If yes, how much has this bothered you?

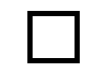

not at all

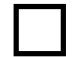

a little

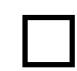

moderately

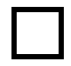

a lot 


\begin{tabular}{|l|l|}
\hline 33 (a) & Have you had sleep problems (e.g. insomnia) in recent weeks? \\
& No $\square$ If no, go to next symptom \\
& Yes $\square$ If yes, complete (b) \\
\hline (b) & If yes, how much has this bothered you? \\
& \\
& not at all
\end{tabular}

\begin{tabular}{|l|l|}
\hline 34 (a) & Have you felt generally weak in recent weeks? \\
& No $\square$ If no, go to next symptom \\
& Yes $\square$ If yes, complete (b) \\
\hline (b) & If yes, how much has this bothered you? \\
& not at all \\
& a little
\end{tabular}

\begin{tabular}{|l|l|}
\hline 35 (a) & Have you had a poor appetite in recent weeks? \\
& No $\square$ If no, go to next symptom \\
& Yes $\square$ If yes, complete (b) \\
\hline (b) & If yes, how much has this bothered you? \\
& \\
& not at all
\end{tabular}

\begin{tabular}{|l|l|}
\hline 36 (a) & Have you lost weight in recent weeks? \\
& No $\square$ If no, go to next symptom \\
& Yes $\square$ If yes, complete (b) \\
\hline (b) & If yes, how much has this bothered you? \\
& $\square$ \\
not at all & a little
\end{tabular}

\begin{tabular}{|l|l|l|}
\hline 37 (a) & Have you gained weight in recent weeks? \\
& No $\square$ If no, go to next symptom \\
& Yes $\square$ If yes, complete (b) \\
\hline (b) & If yes, how much has this bothered you? \\
& \\
&
\end{tabular}




\begin{tabular}{|l|l|}
\hline 38 (a) & Have you had indigestion or heartburn in recent weeks? \\
& No $\square$ If no, go to next symptom \\
& Yes $\square$ If yes, complete (b) \\
\hline (b) & If yes, how much has this bothered you? \\
& \\
& not at all
\end{tabular}

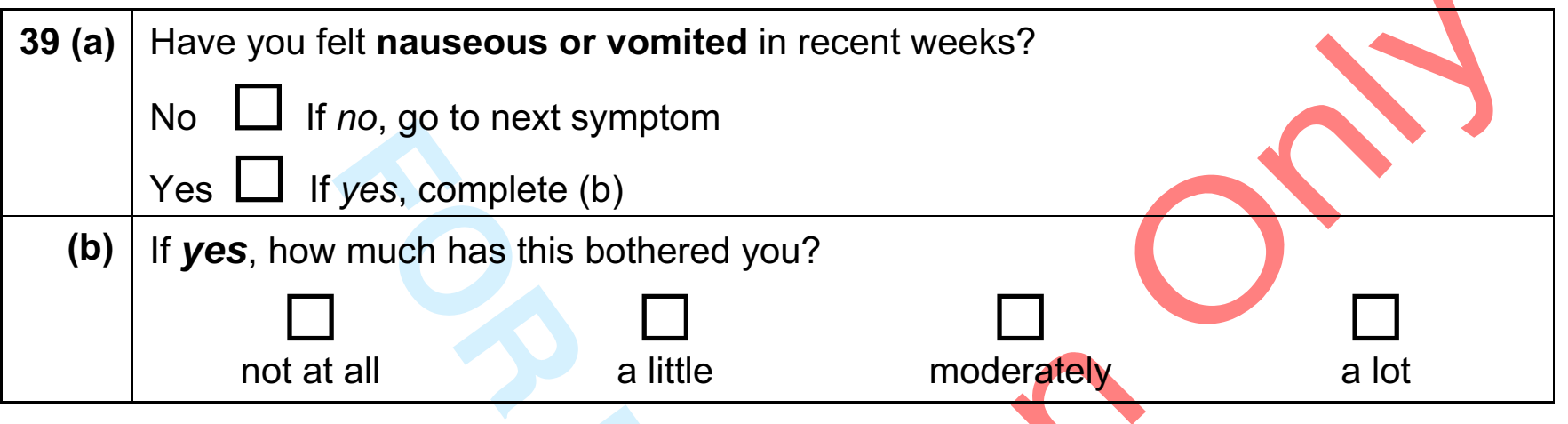

\begin{tabular}{|l|l|l|}
40 (a) & Have you had excessive flatulence or belching (wind) in recent weeks? \\
& No $\square$ If no, go to next symptom \\
& Yes $\square$ If yes, complete (b) \\
(b) & If yes, how much has this bothered you? \\
& \\
not at all & a little
\end{tabular}

\begin{tabular}{|l|l|l|}
\hline 41 (a) & Have you felt bloated in recent weeks? \\
& No $\square$ If no, go to next symptom \\
& Yes $\square$ If yes, complete (b) \\
\hline (b) & If yes, how much has this bothered you? \\
& $\square$ \\
not at all
\end{tabular}

42 (a) Have you had diarrhoea in recent weeks?

No $\square$ If no, go to next symptom

Yes $\square$ If yes, complete (b)

(b) If yes, how much has this bothered you?

$\begin{array}{lccc}\square & \square & \square & \square \\ \text { not at all } & \text { a little } & \text { moderately } & \text { a lot }\end{array}$




\begin{tabular}{|l|l|}
\hline 43 (a) & Have you had constipation in recent weeks? \\
& No $\square$ If no, go to next symptom \\
& Yes $\square$ If yes, complete (b) \\
\hline (b) & If yes, how much has this bothered you? \\
& \\
& not at all
\end{tabular}

\begin{tabular}{|l|l|}
\hline 44 (a) & Have you had difficulty urinating in recent weeks? \\
& No $\square$ If no, go to next symptom \\
& Yes $\square$ If yes, complete (b) \\
\hline (b) & If yes, how much has this bothered you? \\
& $\square$ \\
& not at all
\end{tabular}

Have you had any symptoms in recent weeks not already mentioned above?

Yes $\square$ No $\square$ If 'yes', please complete one or more of the boxes below

\begin{tabular}{|l|l|}
\hline (a) & Have you,---1 \\
& No $\square$ If no, go to next symptom \\
& Yes $\square$ If yes, complete (b) \\
\hline (b) & If yes, how much has this / have these bothered you? \\
& \\
& not at all
\end{tabular}

\begin{tabular}{|l|l|}
\hline (a) & Have you \\
No $\square$ If no, go to next symptom \\
Yes $\square$ If yes, complete (b) \\
(b) If yes, how much has this / have these bothered you? \\
$\square \quad \square \quad$ moderately \\
not at all
\end{tabular}

\section{Thank you for completing this questionnaire}




\section{AneurysmTSQ \\ (Aneurysm Treatment Satisfaction Questionnaire)}

The following questions are concerned with your experience of aortic aneurysm treatment, including any:

- monitoring

- medication

- operation

Please answer each question by circling a number on each of the scales.

1. How satisfied are you with your aneurysm treatment (including monitoring)? $\begin{array}{llllllllll}\text { very satisfied } & 6 & 5 & 4 & 3 & 2 & 1 & 0 & \text { very dissatisfied }\end{array}$

2. How convenient have you found your treatment (including monitoring)? $\begin{array}{lllllllll}\text { very convenient } & 6 & 5 & 4 & 3 & 2 & 1 & 0 & \text { very inconvenient }\end{array}$

3. How bothered are you by any discomfort or pain related to your aneurysm and/or its treatment recently?

not at all bothered $6 \quad 6 / 4 / 3 \quad 2 \quad 1 \quad 0 \quad$ very bothered

4. Were you given any information about the following aspects of treatment for your aneurysm? Please tick one box for each aspect of treatment below.

- Monitoring

- Operation (stent or open-repair)

- Side effects

- Follow up

Recommended or restricted activities/movements

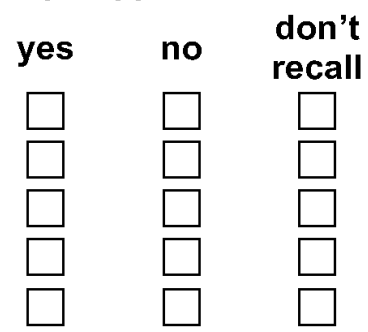

4a. Were you given any of the above information in written form for you to take home?

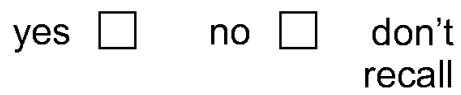

4b. How satisfied are you with information provided about your aneurysm and its treatment?

$\begin{array}{lllllllll}\text { very satisfied } & 6 & 5 & 4 & 3 & 2 & 1 & 0 & \text { very dissatisfied }\end{array}$


AneurysmTSQ continued...

5. How satisfied are you with feedback about scan results?

$\begin{array}{lllllllll}\text { very satisfied } & 6 & 5 & 4 & 3 & 2 & 1 & 0 & \text { very dissatisfied }\end{array}$

6. How satisfied are you with the amount of support you are getting from nurses, doctors and other clinical staff in treating your aneurysm?

$\begin{array}{lllllllll}\text { very satisfied } & 6 & 5 & 4 & 3 & 2 & 1 & 0 & \text { very dissatisfied }\end{array}$

7. How satisfied are you with your understanding of the treatment for your aortic aneurysm (including any operation / monitoring)?

$\begin{array}{lllllllll}\text { very satisfied } & 6 & 5 & 4 & 3 & 2 & 1 & 0 & \text { very dissatísfied }\end{array}$

8. Have you had an operation for your aneurysm (i.e. stent or open repair)? yes $\square$ no

If 'yes', please answer all the remaining questions.

If 'no', please go to Question 12.

8a. How satisfied were you with the length of your stay in hospital?

$\begin{array}{llllllllll}\text { very satisfied } & 6 & 5 & 4 & 3 & 2 & 1 & 0 & \text { very dissatisfied }\end{array}$

8b. Please consider the length of your stay in hospital for the operation. Did you feel that this was: (please tick one box)

- too short

- just right

- too long

9. How bothered are you by any side effects or after effects of the treatment for your aneurysm? [If none experienced recently, please tick here $\square$ and go straight to Q.10] $\begin{array}{lllllllll}\text { not at all bothered } & 6 & 5 & 4 & 3 & 2 & 1 & 0 & \text { very bothered }\end{array}$

10a. How satisfied are you with the post-operative follow-up of your condition (including any scans / clinic visits)?

$\begin{array}{lllllllll}\text { very satisfied } & 6 & 5 & 4 & 3 & 2 & 1 & 0 & \text { very dissatisfied }\end{array}$

10b. Please consider the number of postoperative scans / clinic visits you have had. Do you feel that this was: (please tick one box)

- not enough

- just right

- too many

continued on the next page ...

NOT FOR USE: for review by School of Health \& Related Research, University of Sheffield, ref HPR 1758

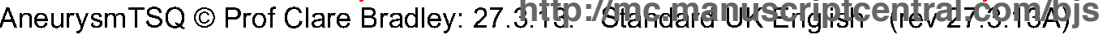


AneurysmTSQ continued ...

11. How likely would you be to encourage someone else with an aneurysm like yours to have your kind of treatment?

$\begin{array}{llllllllll}\text { very likely } & 6 & 5 & 4 & 3 & 2 & 1 & 0 & \text { very unlikely }\end{array}$

Please make sure that you have circled one number on each of the scales above that are applicable to you.

12. Are there any other aspects of your aortic aneurysm treatment (including any monitoring), causing either satisfaction or dissatisfaction, that have not been covered by the questionnaire?

yes $\square$ no

If yes, please describe below.

Thank you for completing this questionnaire. 